This is a peer-reviewed, accepted author manuscript of the following chapter: Fletcher, A., Hashem, A., Farag, S., Taha, G., Badawy, S., \& Mohamed, L. (Accepted/In press). Non-linear adsorption characteristics of modified pine wood sawdust optimised for adsorption of $\mathrm{Cd}(\mathrm{II})$ from aqueous systems. Journal of Environmental Chemical Engineering.

\title{
Non-linear adsorption characteristics of modified pine wood sawdust optimised for
} adsorption of $\mathrm{Cd}(\mathrm{II})$ from aqueous systems

\author{
A. Hashem ${ }^{a *}$, S. M. Badawy ${ }^{b}$, S. Farag ${ }^{a}$, L. A. Mohamed ${ }^{\text {, }}$, A.J. Fletcher ${ }^{d}$ and G. M. Taha ${ }^{a}$
}

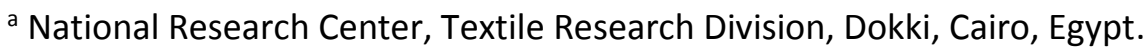

*Email: (alihashem2000@yahoo.com)

${ }^{\mathrm{b}}$ National Center for Clinical and Environmental Toxicology, NECTR, Faculty of Medicine, Cairo University, Egypt.

${ }^{\mathrm{c}}$ Microbial Chemistry Department, National Research Center, Dokki, Cairo, Egypt.

${ }^{d}$ Department of Chemical and Process Engineering, University of Strathclyde, 75 Montrose Street, Glasgow, G1 1XJ, UK.

\section{Abstract}

The facile modification of pinewood sawdust, with maleic acid, to produce a sorbent aimed at metal ion adsorption, was tested via the batch adsorption of $\mathrm{Cd}(\mathrm{II})$ ions from aqueous solution. The sorbent was characterized for the $\mathrm{pH}$ of zero point charge $\left(\mathrm{pH}_{\mathrm{zPc}}\right)$, spectroscopic evaluation of the surface functionalization, structural and morphological features. Factors affecting adsorption behavior, such as adsorbent dose, $\mathrm{pH}$ of solution, contact time and $\mathrm{Cd}(\mathrm{II})$ ion concentration were investigated. Results obtained show the adsorption rate to be comparatively fast, with equilibrium achieved after $\sim 35 \mathrm{~min}$. Subsequent analysis, showed Langmuirian behavior and a monolayer adsorption capacity of $180.4 \mathrm{mg} \mathrm{g}^{-1}$, at $\mathrm{pH}$ 6; while data derived from two-parameter and three-parameter isotherm models was evaluated using non-linear regression methods, with error analysis, to determine the most appropriate model and allow prediction of optimum parameters. The Sips isotherm model proved the most appropriate in describing the experimental data obtained in the study; with a low level of heterogeneity in the adsorption sites occupied suggesting the interaction of the metal ions is 
This is a peer-reviewed, accepted author manuscript of the following chapter: Fletcher, A., Hashem, A., Farag, S., Taha, G., Badawy, S., \& Mohamed, L. (Accepted/In press). Non-linear adsorption characteristics of modified pine wood sawdust optimised for adsorption of Cd(II) from aqueous systems. Journal of Environmental Chemical Engineering.

preferential with the added carboxylate moieties only. Additionally, the rate of adsorption was analysed using a range of kinetic models (pseudo-first-order, pseudo-second-order, Bangham and Elovich) in their non-linear forms to provide insight into the adsorption mechanism and showing pseudo-second order behavior is observed, indicating two processes are key in the adsorption process, likely diffusion to the surface and subsequent adsorption on the carboxylate moieties incorporated by chemical modification. In conclusion, the sorbent produced in this study offers high potential for the removal of $\mathrm{Cd}$ (II) ions from aqueous solution due to the carboxylic functionalities incorporated into the material, which is optimized by solution $\mathrm{pH}$ and adsorbent dose.

Keywords: Maleic acid; Isotherm models; Adsorption kinetics.

\section{Introduction}

The persistent presence of heavy metals in drinking water, and industrial wastes, has been identified as a global health problem, as these species cannot be biologically degraded like organic contaminants.

As a consequence, the removal of heavy metals from water systems has attracted significant attention, which has increased in recent years, with a growing understanding of the toxicity of these species towards human health, aquatic life, flora and fauna[1].

Cadmium has been identified as a major heavy metal pollutant, with a proven high degree of toxicity at very low exposure levels, which can result in acute disorders and various chronic diseases by accumulation in living organisms [2]. This metal is discharged from central industries, like the mining, oil refineries, metal plating, batteries, alloy industries, smelting, phosphate fertilisers and pigments [3-5], resulting in cadmium contaminated water courses.

Adsorption by biomaterials has been proven to be highly effective for the removal of pollutants, including heavy metals from water and wastewater streams, with associated economic benefits, making it a potential alternative treatment route, preferable to conventional techniques such as ion 
This is a peer-reviewed, accepted author manuscript of the following chapter: Fletcher, A., Hashem, A., Farag, S., Taha, G., Badawy, S., \& Mohamed, L. (Accepted/In press). Non-linear adsorption characteristics of modified pine wood sawdust optimised for adsorption of Cd(II) from aqueous systems. Journal of Environmental Chemical Engineering.

exchange, precipitation, reverse osmosis and electrode position. Activated carbon is a relatively inexpensive material, which has been used extensively as an adsorbent in wastewater treatment systems but it is unsuitable for developing countries due to the operational cost of such processes[68].

Agricultural waste materials offer potential adsorbents in the removal of heavy metals from wastewater [9] and the use of such free resources, which are widely available and incur low processing costs, offers an alternative to the comparatively costly activated carbon, while retaining the favourable physico-chemical properties often associated with latter adsorbents. Sawdust is a natural resource, mainly consisting of cellulose and lignin that has high adsorption capacity for pollutants [10, 11], and has potential for adsorption of key pollutants, such as, heavy metals, oils, dyes and toxic salts from water.

In recent years, modified cellulosic materials has been widely investigated, where potential functional groups are introduced into the material by reaction with hydroxyl moieties present on the backbone of the cellulose chain, which can improve adsorption, or covalent binding, of metal ions [12]. Polysulfide treated sawdust was very effective for the removal of divalent cobalt from aqueous solution [13], while copper-impregnated sawdust exhibits significant arsenic(III) removal [14]. Sawdust treated with phosphates has proven more effective for chromium removal as opposed to untreated sawdust [15]. Dye-treated sawdust was used long time ago for the removal of heavy metal ions from waste water, [16, 17]. The esterification process increases the carboxylic content of the wood fibre surface leading to a corresponding increase in the sorption of divalent metal ions [18]. The cadmium(II) binding capacity of the modified sawdust with carboxyl groups using succinic anhydride could reach uptakes of up to $169 \mathrm{mg} \mathrm{g}^{-1}$ [19]. The amidoximated sawdust had a high adsorption capacity for $\mathrm{Cu}(\mathrm{II})$ of $246 \mathrm{mg} \mathrm{g}^{-1}$ and for $\mathrm{Ni}(\mathrm{II})$ of $188 \mathrm{mg} \mathrm{g}^{-1}$ [20]. The modified sawdusts using polyacrylic chains possessed $15-40$ times higher adsorption capacity for $\mathrm{Cu}(\mathrm{II}), \mathrm{Ni}(\mathrm{II})$ and $\mathrm{Cd}(\mathrm{II})$ than the unmodified sawdusts [21]. The 
This is a peer-reviewed, accepted author manuscript of the following chapter: Fletcher, A., Hashem, A., Farag, S., Taha, G., Badawy, S., \& Mohamed, L. (Accepted/In press). Non-linear adsorption characteristics of modified pine wood sawdust optimised for adsorption of Cd(II) from aqueous systems. Journal of Environmental Chemical Engineering.

adsorption isotherms describe the phenomenon governing the mobility of a substance from the aqueous porous media or aquatic environments to a solid-phase at a constant temperature and $\mathrm{pH}[22,23]$.

Based on this rationale, this work is aimed at the modification of sawdust with maleic acid to enhance the adsorption capacity of the resulting material for the removal of $\mathrm{Cd}(\mathrm{II})$ ions from aqueous solutions. The effects of altering selected reaction conditions, such as $\mathrm{pH}$, contact time and temperature, on the adsorption capacity of the modified sawdust were investigated, and non-linear regression methods were determine the most appropriate thermodynamic and kinetic adsorption models for this system.

\section{Experimental}

\subsection{Materials and reagents}

Pinewood sawdust (SD), obtained from local wood manufacturing companies, was washed with distilled water several times to remove any adhered particles, and subsequently dried at $353 \mathrm{~K}$ for $24 \mathrm{~h}$, and sieved to pass through a $50-150 \mu \mathrm{m}$ mesh. Adsorbent structure and surface moieties were characterised using X-ray diffraction (XRD), Fourier transform infrared (FTIR) spectroscopy, scanning electron microscopy (SEM) and energy-dispersive X-ray fluorescence (EDX) analysis. Cadmium acetate, EDTA, maleic acid, acetic acid, sodium carbonate, acetone and ethyl alcohol were supplied as lab grade chemicals from Merck (Germany), and used as received.

\subsection{Methods}

\subsubsection{Preparation of the adsorbent}

The adsorbent was prepared by placing $2 \mathrm{~g}$ of SD powder in a beaker and adding a known weight of maleic acid pre-dissolved in water; the resulting mixture was stirred with a spatula. The homogeneous paste obtained was dried in an oven at $373-413 \mathrm{~K}$, before subsequent cooling to room temperature. The sample was washed periodically with a solution of ethanol/water (80:20) for $2 \mathrm{~h}$ to remove any unreacted maleic acid and soluble by-products, before drying at $333 \mathrm{~K}$ for $4 \mathrm{~h}$. 
This is a peer-reviewed, accepted author manuscript of the following chapter: Fletcher, A., Hashem, A., Farag, S., Taha, G., Badawy, S., \& Mohamed, L. (Accepted/In press). Non-linear adsorption characteristics of modified pine wood sawdust optimised for adsorption of Cd(II) from aqueous systems. Journal of Environmental Chemical Engineering.

97

98

99

FTIR spectroscopy was used to determine the functional moieties present on the surface of the SD

\subsubsection{Batch adsorption studies}

A weighed quantity of adsorbent $(\sim 0.05 \mathrm{~g})$ was added to $100 \mathrm{~mL}$ of a $\mathrm{Cd}(\mathrm{II})$ ion solution (100$1000 \mathrm{mg} \mathrm{L}^{-1}$ ) in a $125 \mathrm{~mL}$ Erlenmeyer flask. $0.1 \mathrm{M} \mathrm{HNO}_{3}$ or $0.1 \mathrm{M} \mathrm{NaOH}$ was added dropwise to adjust $\mathrm{pH}$ values and the mixture shaken at constant speed $(150 \mathrm{rpm})$ at $303 \mathrm{~K}$ for a pre-defined period of time, before filtering to separate the metal ion solutions. The concentration of $\mathrm{Cd}(\mathrm{II})$ ions was measured before and after adsorption, using direct titration with a standard EDTA solution (0.0005 M).

The amount of adsorbed $\mathrm{Cd}(\mathrm{II})$ at equilibrium, $q_{e}\left(\mathrm{mg} \mathrm{g}^{-1}\right)$ was calculated using:

$$
q_{e}=\frac{V\left(C_{o}-C_{e}\right)}{W}
$$

While the percentage removal was calculated via:

$$
\text { Removal \% }=\frac{\left(C_{o}-C_{e}\right)}{C_{o}} \cdot 100
$$

where $C_{o}$ and $C_{e}\left(\mathrm{mg} \mathrm{L}^{-1}\right)$ are the initial metal concentration and metal concentration at equilibrium, respectively; $W(\mathrm{~g})$ is the weight of adsorbent used; and $V$ is the volume of $\mathrm{Cd}(\mathrm{II})$ solution $(0.1 \mathrm{~L})$.

\subsection{Analyses}

\subsubsection{Surface chemistry}

The $\mathrm{pH}$ at zero charge $\left(\mathrm{pH}_{\mathrm{pzc}}\right)$ of the adsorbent sample, also known as the point of zero charge, is the point at which the initial $\mathrm{pH}$ value $\left(\mathrm{pH}_{\text {initial }}\right)$ equals the final $\mathrm{pH}$ of the solution $\left(\mathrm{pH}_{\text {final }}\right)$. This was determined by adjusting the initial $\mathrm{pH}$ value $\left(\mathrm{pH}_{\text {initial }}\right)$ of $100 \mathrm{ml}$ of $0.01 \mathrm{~N} \mathrm{NaCl}$ solutions in the range 212, using $0.01 \mathrm{~N} \mathrm{HCl}$ solution and $0.01 \mathrm{~N} \mathrm{NaOH} . \mathrm{A} 0.1 \mathrm{~g}$ of the adsorbent sample was added into each $0.01 \mathrm{~N} \mathrm{NaCl}$ solution adjusted to a constant initial $\mathrm{pH}$ value. After $24 \mathrm{~h}$, to allow for equilibration, the final $\mathrm{pH}$ of the solution $\left(\mathrm{pH}_{\text {final }}\right)$ was recorded and plotted against $\mathrm{pH}_{\text {initial. }}$.

adsorbents before and after treatment with maleic acid, and after loading with $\mathrm{Cd}(\mathrm{II})$ ions. The 
This is a peer-reviewed, accepted author manuscript of the following chapter: Fletcher, A., Hashem, A., Farag, S., Taha, G., Badawy, S., \& Mohamed, L. (Accepted/In press). Non-linear adsorption characteristics of modified pine wood sawdust optimised for adsorption of Cd(II) from aqueous systems. Journal of Environmental Chemical Engineering.

117

averaged FTIR spectra were recorded over $4000-400 \mathrm{~cm}^{-1}$ (scan interval: $1 \mathrm{~cm}^{-1}$, number of scans: 120 ) using $\mathrm{KBr}$ discs containing $\sim 2-10 \mathrm{mg}$ of sample in $\sim 300 \mathrm{mg}$ of $\mathrm{KBr}$, on Perkin-Elmer spectrophotometer Carboxyl group contents of the adsorbent samples were estimated [24] by adding $0.2 \mathrm{~g}$ of the adsorbent to a $125 \mathrm{~mL}$ flask containing $50 \mathrm{~mL}$ of $\mathrm{NaOH}$ solution $(0.03 \mathrm{~N})$. The flasks were left overnight at room temperature, after which their contents were titrated with standard $\mathrm{HCl}$ solution $(0.01 \mathrm{~N})$ using a phenolphthalein indicator. The carboxyl content of the adsorbent sample was subsequently calculated using:

$$
\text { Carboxyl group content }=\frac{100 N\left(V_{o}-V_{i}\right)}{W}=\frac{[\mathrm{COOH}] \mathrm{m} . \mathrm{eq} .}{100 \text { gsample }}
$$

where $V_{o}$ is the volume of $\mathrm{HCl}(\mathrm{mL})$ consumed without the addition of the adsorbent in a blank experiment, $V_{i}$ is the volume of $\mathrm{HCl}(\mathrm{mL})$ consumed in the back titration of the adsorbent containing solution, $N$ is the normality of the standard $\mathrm{HCl}$ solution $(0 . \mathrm{XX} \mathrm{N})$, and $\mathrm{W}$ is the weight of the adsorbent sample (0.2 g).

\subsubsection{Adsorbent morphology}

The samples studied by SEM were coated with a thin layer of gold using a diode sputter unit, before analysis using a scanning electron microscope (model JEOL-JSM-5600), at an accelerating voltage of $25.0 \mathrm{kV}$. Elemental analysis was performed using an EDX spectrometer (Oxford Instruments 6587 EDX detector), attached to the JEOL-JSM-5600 unit used for SEM.

XRD patterns was measured in continuous scanning mode on a PANalytical diffractometer (X'Pert PRO) using a $\mathrm{Cu}$ tube. Diffraction intensities were recorded from 2 to $60^{\circ}$, and the diffraction patterns obtained for the samples studied were compared with JCPDS (Joint Committee on Powder Diffraction Standards) patterns. 
This is a peer-reviewed, accepted author manuscript of the following chapter: Fletcher, A., Hashem, A., Farag, S., Taha, G., Badawy, S., \& Mohamed, L. (Accepted/In press). Non-linear adsorption characteristics of modified pine wood sawdust optimised for adsorption of Cd(II) from aqueous systems. Journal of Environmental Chemical Engineering.

Textural characterization of materials used in this study was performed using nitrogen adsorption isotherms measured at $77 \mathrm{~K}$, using a Micromeritics ASAP 2420. Isotherms were used to calculate specific surface areas, total pore volumes, etc. (see Supporting Information).

\subsection{Isotherm Analyses}

The experimental isotherm data obtained in this study were analysed using four isotherm models based on two parameters, i.e. Langmuir, Freundlich, Dubinin-Radushkevich and Temkin, and four isotherm models based on three parameters, i.e. Sips, Redlich-Peterson, Khan and Toth.

\subsubsection{Two-parameter isotherm models}

\subsubsection{Langmuir isotherm model}

The Langmuir Equation [25] is based on monolayer adsorption with a fixed number of localised sites; the model refers to homogeneous adsorption, meaning that the adsorption activation energy and the enthalpies evolved by each adsorbate molecule are equal, in addition there are no interactions between neighbouring adsorbate molecules, nor any site to site movement of adsorbed species. The non-linear form of the Langmuir isotherm is:

$$
q_{e}=\frac{K_{L} C_{e}}{1+b C_{e}}
$$

where $C_{e}$ is the concentration of $\mathrm{Cd}$ (II) ions adsorbed at equilibrium, $\mathrm{mg} \mathrm{L}^{-1}, q_{e}$ is the amount of $\mathrm{Cd}$ (II) ions adsorbed per unit mass of adsorbent $\left(\mathrm{mg} \mathrm{g}^{-1}\right), K_{L}\left(\mathrm{~L} \mathrm{~g}^{-1}\right)$ and $b\left(\mathrm{~L} \mathrm{mg}^{-1}\right)$ are constants, and the ratio $b / k_{L}$ gives the maximum adsorption capacity $\left(q_{\max }\right)$ in $\mathrm{mg} \mathrm{g}^{-1}$. The essential characteristics of Langmuirian behaviour can be expressed in terms of the dimensionless separation factor, $R_{L},[26]$ represented by:

$$
R_{L}=\frac{1}{\left(1+b \cdot C_{0}\right)}
$$

where $C_{o}$ is the initial adsorptive concentration in solution, and $b$ is a constant. The data presented in 
This is a peer-reviewed, accepted author manuscript of the following chapter: Fletcher, A., Hashem, A., Farag, S., Taha, G., Badawy, S., \& Mohamed, L. (Accepted/In press). Non-linear adsorption characteristics of modified pine wood sawdust optimised for adsorption of Cd(II) from aqueous systems. Journal of Environmental Chemical Engineering.

\subsubsection{Freundlich isotherm model}

The Freundlich isotherm can be applied to systems that exhibit multilayer adsorption, mathematically predicting infinite surface coverage at high adsorptive concentrations, and accounts for surface heterogeneity, where the strongest binding sites are occupied first, and the total amount adsorbed is the cumulative adsorption across all surface sites. The decrease in heats of adsorption across all surface sites is assumed to be logarithmic, and the logarithmic form of the model is [27]:

$$
q_{e}=K_{F} \cdot C_{e}^{1 / n}
$$

165

166

where $C_{e}$ and $q_{e}$ are as defined above, and $K_{F}$ and $n$ are constants related to the adsorption capacity and favourability, respectively.

\subsubsection{Temkinisotherm model}

The Temkin isotherm model [28] assumes that there is a linear decrease in the distribution of heats of adsorption across all surface sites due to adsorbate/adsorbent interactions, rather than the logarithmic trend assumed in the Freundlich model. The non-linear Temkin isotherm model is represented by:

$$
q_{e}=\frac{R T}{b_{T}} \cdot \ln \left(A_{T} C_{e}\right)
$$

where $C_{e}$ and $q e$ are as defined above, $A_{T}$ is the Temkin isotherm constant $\left(\mathrm{L} \mathrm{g}^{-1}\right), b_{T}$ is a constant related to the heat of adsorption $\left(\mathrm{J} \mathrm{mol}^{-1}\right), T$ is absolute temperature $(\mathrm{K})$, and $R$ is the universal gas constant $\left(8.314 \mathrm{~J} \mathrm{~mol}^{-1} \mathrm{~K}^{-1}\right)$.

\subsubsection{Dubinin-Radushkevich (D-R) isotherm model}

The Dubinin-Radushkevich model was developed for adsorption onto a heterogeneous surface where the energy of sites is Gaussian distribution. The non-linear Dubinin-Radushkevich isotherm model is [29]: 
This is a peer-reviewed, accepted author manuscript of the following chapter: Fletcher, A., Hashem, A., Farag, S., Taha, G., Badawy, S., \& Mohamed, L. (Accepted/In press). Non-linear adsorption characteristics of modified pine wood sawdust optimised for adsorption of $\mathrm{Cd}(\mathrm{II})$ from aqueous systems. Journal of Environmental Chemical Engineering.

$$
q_{e}=q_{D} \cdot \exp \left\{-B_{D}\left[R T\left(1+\frac{1}{C_{e}}\right)\right]^{2}\right\}
$$

179 Where $C_{e}$ and $q_{e}$ are as defined above, $B_{D}$ is a constant related to the free energy of adsorption per 180 mole of adsorbate $\left(\mathrm{mol}^{2} \mathrm{~kJ}^{-2}\right), q_{D}$ is a constant related to the degree of adsorption on the adsorbent surface, $T$ is absolute temperature (K). The mean free energy per adsorbate molecule, $E\left(\mathrm{~kJ} \mathrm{~mol}^{-1}\right)$, can be calculated using:

$$
E=\frac{1}{\sqrt{2 B_{D}}}
$$

\subsubsection{Three-parameter isotherm models}

\subsubsection{Redlich-Peterson isotherm model}

The Redlich-Peterson isotherm model [30] combines features from both the Freundlich the Langmuir

isotherm models. The non-linear Redlich-Peterson equation is represented by:

$$
q_{e}=\frac{A \cdot C_{e}}{1+B \cdot C_{e}^{g}}
$$

\subsubsection{Toth isotherm model}

192 The Toth isotherm model [31] is another form used to describe heterogeneous adsorption system; it

where $C_{e}$ and $q_{e}$ are as defined above, $A\left(\mathrm{~L} \mathrm{~g}^{-1}\right)$ and $B$ are constants, and $g$ is an exponent constant that lies between 1 and 0 ; when $g=1$, Eq. (12) reduces to the Langmuir equation, and when $g=0$, Eq. (12) reduces to Henry's equation, where $A /(1+B)$ is the Henry's constant. differs by satisfying both low- and high-end concentration boundaries, as expressed by:

$$
q_{e}=\frac{k_{T} \cdot C_{e}}{\left(a_{T}+C_{e}\right)^{\frac{1}{t}}}
$$


This is a peer-reviewed, accepted author manuscript of the following chapter: Fletcher, A., Hashem, A., Farag, S., Taha, G., Badawy, S., \& Mohamed, L. (Accepted/In press). Non-linear adsorption characteristics of modified pine wood sawdust optimised for adsorption of $\mathrm{Cd}(\mathrm{II})$ from aqueous systems. Journal of Environmental Chemical Engineering.

194

where $C_{e}$ and $q_{e}$ are as defined above, $K_{T}$ is a constant, $a_{T}$ is the maximum adsorption capacity, and $1 / \mathrm{t}$ is the Toth exponent constant. It should be noted that this isotherm model reduces to the Langmuir isotherm model, when $\mathrm{t}$ is close to unity.

\subsubsection{Sips isotherm model}

The Sips isotherm model [32] is a combined form of the Langmuir and Freundlich isotherm models. The Sips model can be represented by:

$$
q_{e}=\frac{k_{s} \cdot C_{e}^{\beta_{1}}}{1+a_{s} \cdot C_{e}^{\beta_{1}}}
$$

where $C_{e}$ and $q_{e}$ are as defined above, $k_{s}\left(\mathrm{~L} \mathrm{~g}^{-1}\right)$ and $a_{s}\left(\mathrm{~L} \mathrm{mg}^{-1}\right)$ are constants, and $B_{s}$ is the Sips model exponent. This model reduces to the Freundlich isotherm model at low adsorptive concentrations, and predicts monolayer adsorption, characteristic of the Langmuir isotherm model, at high adsorptive concentrations.

\subsubsection{Khan isotherm model}

The Khan isotherm model [33] was first proposed to describe the adsorption of aromatics on activated carbons, but is also applicable to the system studied here, and is expressed by:

$$
q_{e}=\frac{q_{\max } \cdot b_{K} \cdot C_{e}}{\left(1+b_{K} \cdot C_{e}\right)^{a_{K}}}
$$

where $C_{e}$ and $q_{e}$ are as defined above, $b_{k}$ is a constant, $a_{k}$ is the model exponent, and $q_{\max }$ is the maximum adsorption capacity $\left(\mathrm{mg} \mathrm{g}^{-1}\right)$.

\subsection{Error analysis}

In order to determine the most accurate model of the isothermal data obtained in this study, the error distribution between the experimental data and the data derived from predicted isotherm models 
This is a peer-reviewed, accepted author manuscript of the following chapter: Fletcher, A., Hashem, A., Farag, S., Taha, G., Badawy, S., \& Mohamed, L. (Accepted/In press). Non-linear adsorption characteristics of modified pine wood sawdust optimised for adsorption of $\mathrm{Cd}(\mathrm{II})$ from aqueous systems. Journal of Environmental Chemical Engineering.

213

214

215

216

was minimised using error functions. The variance between experimental data and predicted isotherm data $\left(R^{2}\right)$ was optimised using the solver add-in of Microsoft Excel.

The optimization procedure for the isotherm studies requires an error function to be defined to evaluate the fit of the isotherm model to the experimental equilibrium data. The common error functions used here to optimise the isotherm parameters were: average relative error (ARE), average percentage error (APE\%), hybrid fractional error function (HYBRID), a determinant of the quality of the fit $\left(\chi^{2}\right)$, and normalised standard deviation ( $\left.\Delta \mathrm{q} \%\right)$ [34-38] (Table 1).

Table 1: List of non-linear error functions used for data analysis in this study.

\begin{tabular}{|c|c|c|}
\hline Error Function & Equation & References \\
\hline $\begin{array}{l}\text { Average Relative Error } \\
\text { (ARE) }\end{array}$ & $A R E=\sum_{i=1}^{n}\left|\frac{\left(q_{e}\right)_{\text {exp. }}-\left(q_{e}\right)_{\text {calc. }}}{\left(q_{e}\right)_{\text {exp. }}}\right|$ & 34 \\
\hline $\begin{array}{l}\text { Average Percentage Error } \\
\qquad \text { (APE \%) }\end{array}$ & $A P E \%=\frac{\sum_{i=1}^{N}\left|\left[\left(\left(q_{e}\right)_{\text {exp. }}-\left(q_{e}\right)_{\text {calc. }}\right) / q_{\text {exp. }}\right]\right|}{N} \times 100$ & 35 \\
\hline $\begin{array}{c}\text { Hybrid Fraction Error } \\
\text { Function (Hybrid) }\end{array}$ & Hybrid $=\frac{100}{n-p} \sum_{i=1}^{n}\left[\frac{\left(\left(q_{e}\right)_{\text {exp. }}-\left(q_{e}\right) c a l c .\right)^{2}}{\left(q_{e}\right)_{\text {exp. }}}\right]_{i}$ & 36 \\
\hline $\begin{array}{l}\text { Nonlinear chi-square } \\
\qquad \operatorname{test}(\chi 2)\end{array}$ & $\chi^{2}=\sum \frac{\left(q_{e . \exp }-q_{\text {e.theoretical }}\right)^{2}}{q_{\text {e.theoretical }}}$ & 37 \\
\hline
\end{tabular}


This is a peer-reviewed, accepted author manuscript of the following chapter: Fletcher, A., Hashem, A., Farag, S., Taha, G., Badawy, S., \& Mohamed, L. (Accepted/In press). Non-linear adsorption characteristics of modified pine wood sawdust optimised for adsorption of $\mathrm{Cd}(\mathrm{II})$ from aqueous systems. Journal of Environmental Chemical Engineering.

\begin{tabular}{|l|l|l|}
\hline $\begin{array}{l}\text { Normalized standard } \\
\text { deviation } \Delta q(\%)\end{array}$ & $\Delta q(\%)=\sqrt{\frac{\left.\operatorname{Sum}\left[\left(q_{t . \mathrm{exp}}-q_{t . \mathrm{cal}}\right) / q_{t . \mathrm{exp}}\right)\right]^{2}}{(n-1)}} x 100$ & 38 \\
\hline
\end{tabular}

\subsection{Adsorption kinetics}

\subsubsection{Pseudo-first order model}

The kinetic process of the pseudo-first order is usually considered physical adsorption and is diffusion controlled. The non-linear mathematical form of the pseudo-first-order model [39] is given by:

$$
q_{t}=q_{e}\left[1-\exp \left(-k_{1} t\right)\right]
$$

where $q_{t}$ is the amount of $\mathrm{Cd}(\mathrm{II})$ ions adsorbed $\left(\mathrm{mg} \mathrm{g}^{-1}\right)$ at time $t(\mathrm{~min}), q_{\mathrm{e}}$ is the amount of $\mathrm{Cd}(\mathrm{II})$ ions adsorbed $\left(\mathrm{mg} \mathrm{g}^{-1}\right)$ at equilibrium, and $k_{1}$ is the rate constant of adsorption $\left(\mathrm{min}^{-1}\right)$.

\subsubsection{Pseudo-second order model}

The pseudo-second order kinetic model [46]can be expressed by:

$$
q_{t}=\frac{k_{2} q_{e}^{2 \cdot t}}{\left(1+k_{2} k_{e} t\right)}
$$

where $q_{t}, q_{e}$ and $t$ are as defined above, and $\mathrm{k}_{2}\left(\mathrm{~g} \mathrm{mg}^{-1} \mathrm{~min}^{-1}\right)$ is the rate constant for the kinetic model.

This model assumes that the rate of adsorption is controlled by the sharing of electrons between the adsorbent and adsorbate, i.e. a chemical process. The intraparticle diffusion model is not appropriate for studies at high adsorption times. To understand the adsorption mass transfer, the use of approximated models like Weber-Morris (intraparticle diffusion model), is not recommended. WeberMorris is only valid for short adsorption times and when the bulk concentration is little affect. 
This is a peer-reviewed, accepted author manuscript of the following chapter: Fletcher, A., Hashem, A., Farag, S., Taha, G., Badawy, S., \& Mohamed, L. (Accepted/In press). Non-linear adsorption characteristics of modified pine wood sawdust optimised for adsorption of $\mathrm{Cd}(\mathrm{II})$ from aqueous systems. Journal of Environmental Chemical Engineering.

\subsubsection{Bangham's equation model}

246 Bangham's kinetic model[40] is expressed by:

$$
q_{t}=q_{e}\left[1-\exp \left(-k_{b} t^{n}\right)\right]
$$

247 where $q_{t}, q_{e}$ and $t$ are as defined above, and $k_{b}$ and $n$ are constants.

\subsection{Elovich model}

249 The Elovich kinetic model [41] is expressed by:

$$
q_{t}=\beta \ln (\alpha \beta t)
$$

where $q_{t}$ and $t$ are as defined above, $\alpha\left(\mathrm{mg} \mathrm{g}^{-1} \mathrm{~min}^{-1}\right)$ is the initial rate of adsorption and $\beta\left(\mathrm{g} \mathrm{mg}^{-1}\right)$ is coverage.

3. Results and discussion

\subsubsection{Fourier transform infrared spectroscopy}


This is a peer-reviewed, accepted author manuscript of the following chapter: Fletcher, A., Hashem, A., Farag, S., Taha, G., Badawy, S., \& Mohamed, L. (Accepted/In press). Non-linear adsorption characteristics of modified pine wood sawdust optimised for adsorption of Cd(II) from aqueous systems. Journal of Environmental Chemical Engineering.

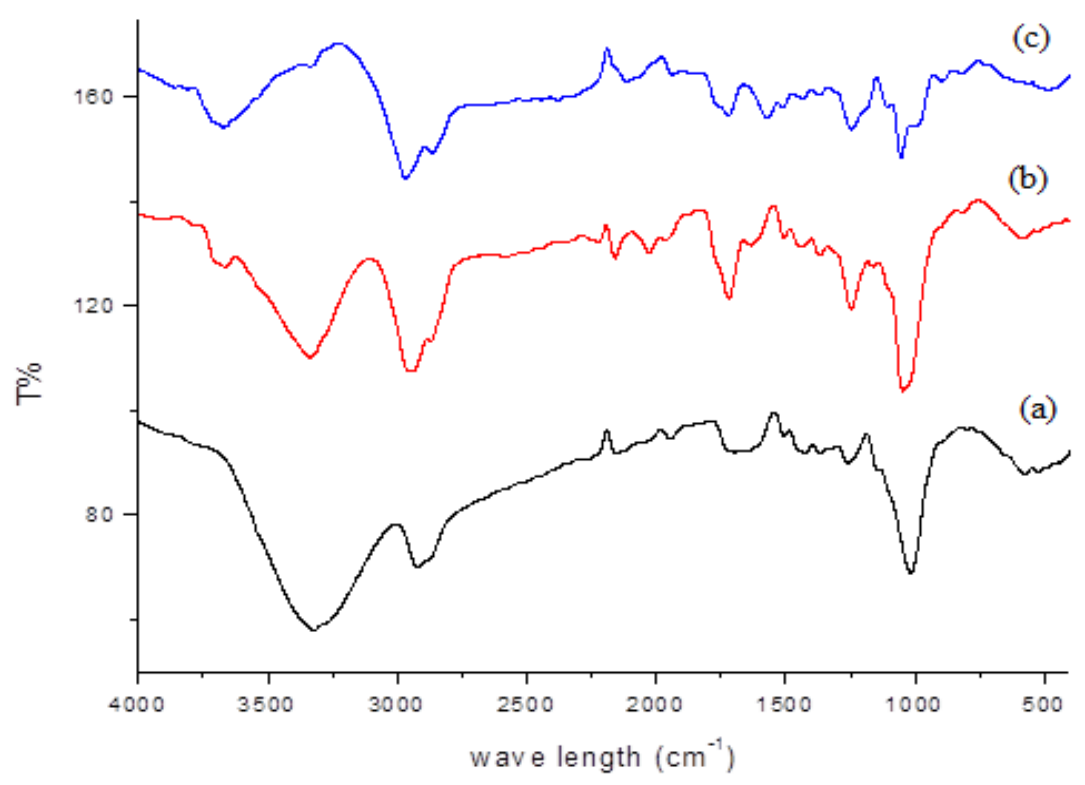

Figure1: FTIR spectra of (a) pinewood sawdust (SD); (b) SD treated with maleic acid (SDTMA); and (c) SDTMA loaded with $\mathrm{Cd}(\mathrm{II})$ ions.

The chemical structures of the pinewood sawdust (SD), sawdust treated with maleic acid (SDTMA) and SDTMA loaded with Cd(II) ions, were determined using FTIR spectroscopy (Figure 1). The SD sample (trace a), exhibited a broad absorption peak at $3322 \mathrm{~cm}^{-1}$, indicating the presence of free and bonded $\mathrm{O}-\mathrm{H}$, due to vibrations of the hydroxyl groups of cellulose, hemi-cellulose, lignin, and water sorbed on the sawdust. The peak observed at $2923 \mathrm{~cm}^{-1}$ corresponds to the stretching vibration of the $\mathrm{C}-\mathrm{H}$ bond in the methyl groups. The weak peaks at 1695 and $1650 \mathrm{~cm}^{-1}$ are characteristic of carbonyl group stretching in ketones and aldehydes, while the strong stretching vibration of $\mathrm{C}-\mathrm{O}\left(1017 \mathrm{~cm}^{-1}\right)$ is specific to hemicelluloses and lignin components of sawdust [42]. Trace b, in Figure 1, shows the appearance of a strong peak at $1719 \mathrm{~cm}^{-1}$ due to the absorption of carbonyl stretching of maleic esters groups. The peak at $1247 \mathrm{~cm}^{-1}$ is attributed to the stretching vibration of C-O, associated with carboxyl groups, and the appearance of a weak peak at $1634 \mathrm{~cm}^{-1}$ can be attributed to the $\mathrm{C}=\mathrm{C}$ vibration in the maleate esters. The modification of the sawdust also led to a decrease of the $\mathrm{O}-\mathrm{H}$ vibration, and an increase of the stretching vibration of the $\mathrm{C}-\mathrm{O}$ band $\left(1017 \mathrm{~cm}^{-1}\right)$. Trace $\mathrm{c}$ shows a decrease in the peaks associated 
This is a peer-reviewed, accepted author manuscript of the following chapter: Fletcher, A., Hashem, A., Farag, S., Taha, G., Badawy, S., \& Mohamed, L. (Accepted/In press). Non-linear adsorption characteristics of modified pine wood sawdust optimised for adsorption of Cd(II) from aqueous systems. Journal of Environmental Chemical Engineering.

(a)

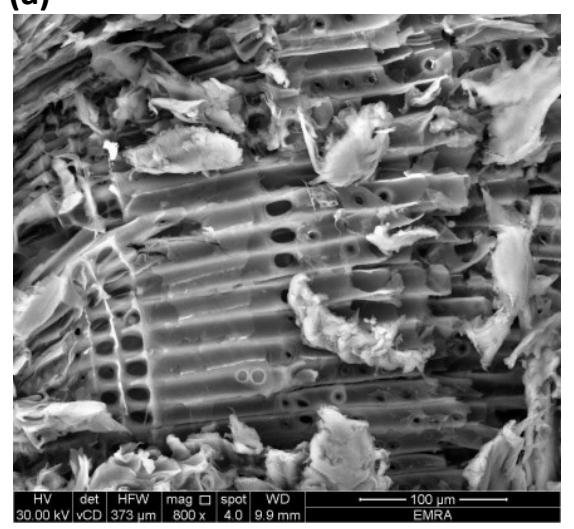

(b)

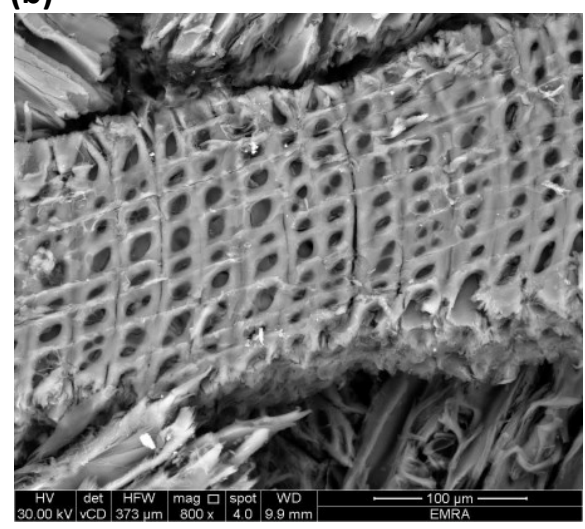

(c)

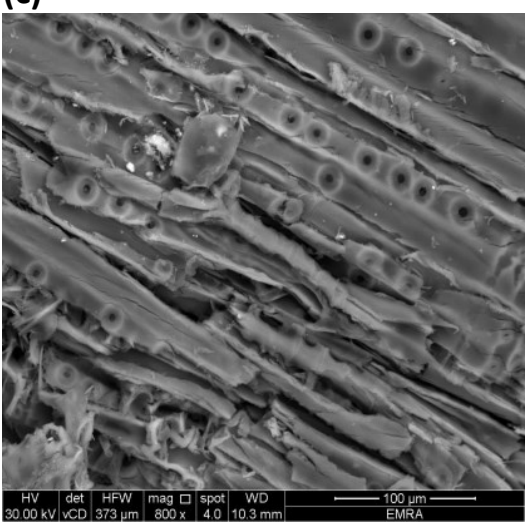

281

Figure 2: Scanning electron micrographs at 800x magnification of (a) pinewood sawdust; (b) SD treated with maleic acid (SDTMA); and (c) SDTMA loaded with Cd(II) ions.

Figure 2 shows SEM images of SD, SDTMA and SDTMA loaded with Cd(II) ions, at a magnification of 800x. SD appears to be a heterogeneous fibrous structure consisting of rough surface having irregular neat layers shapes with pores and cavities that, in nature, would facilitate the diffusion of an adsorptive and provide a high contact area for adsorption of metal ions (Figure 2a). The fibrous structure, and the fibres themselves, are not intrinsically damaged by maleic acid esterification (Figure 2b). Esterification seems to result in a change in the orientation and length of the fibres to shorter and well-ordered structures. The chemical substitution of cellulose damages some favourable properties of the structure, such as porosity. The average size of the pores, evaluated from the magnified image, was found to be $\sim 5 \mu \mathrm{m}$, and these materials present a suitable morphology to retain metal ions. SEM of SDTMA after the adsorption of Cd(II) ions (Figure 2c) seems to show a number of white precipitates on the surface of the fibres, which can be ascribed to adhesion of $\mathrm{Cd}(\mathrm{II})$ ions via favourable interactions 
This is a peer-reviewed, accepted author manuscript of the following chapter: Fletcher, A., Hashem, A., Farag, S., Taha, G., Badawy, S., \& Mohamed, L. (Accepted/In press). Non-linear adsorption characteristics of modified pine wood sawdust optimised for adsorption of $\mathrm{Cd}(\mathrm{II})$ from aqueous systems. Journal of Environmental Chemical Engineering.

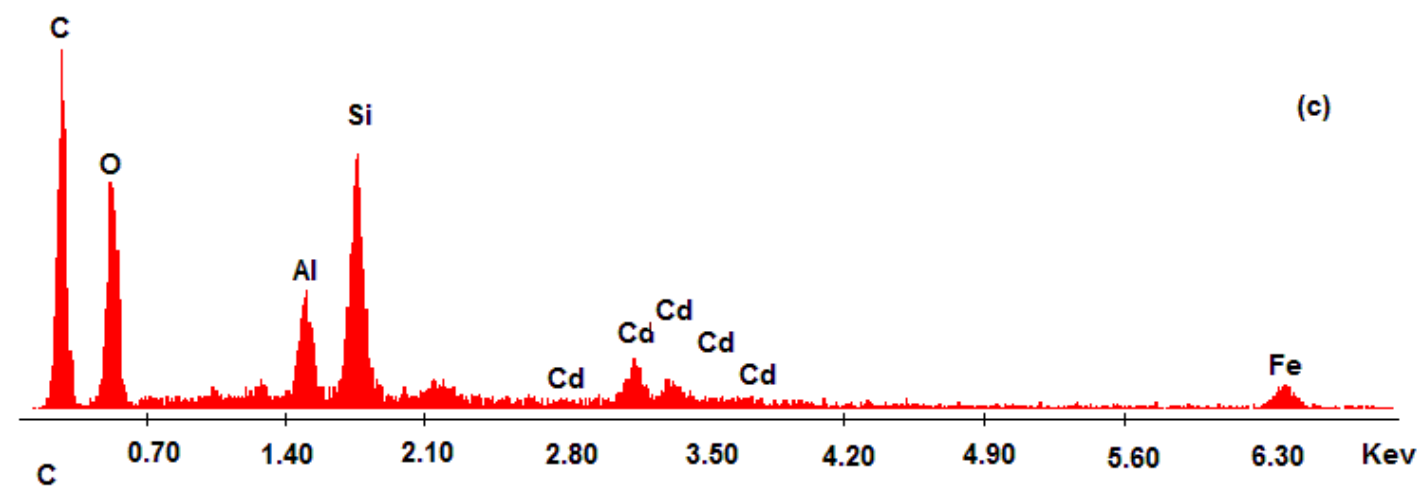

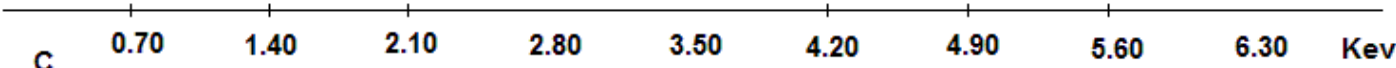

0.70

1.40

2.10

2.80

4.90

5.60

(b)

Figure 3: Energy dispersive X-ray spectra of (a) pinewood sawdust (SD), (b) pinewood sawdust treated with maleic acid (SDTMA); and(c) SDTMA loaded with Cd(II) ions.

\subsubsection{X-ray analysis}

XRD uses elastic scattering of X-rays to allow identification of phase purity and the crystalline nature of analysed materials. The XRD pattern of SD (Figure4) shows features typical of a cellulosic material $\left(\mathrm{C}_{6} \mathrm{H}_{10} \mathrm{O}_{5}\right)_{n}$, which is the main component structure in wood products, with two broad diffraction peaks, one indicating the crystallinity of cellulose, and a broad amorphous background band. The major peak 
This is a peer-reviewed, accepted author manuscript of the following chapter: Fletcher, A., Hashem, A., Farag, S., Taha, G., Badawy, S., \& Mohamed, L. (Accepted/In press). Non-linear adsorption characteristics of modified pine wood sawdust optimised for adsorption of $\mathrm{Cd}(\mathrm{II})$ from aqueous systems. Journal of Environmental Chemical Engineering.

$306(100 \%)$ at 22.74 degrees $(2 \theta)$ is an indicator of the presence of highly crystalline cellulose, while the

307 minor one $(70 \%)$ at 16.66 degrees $(2 \theta)$ is a measure of the less crystalline content from polysaccharides. XRD after treatment reveals the structural modification of cellulose, as a consequence of esterification with maleic acid, and the appearance of three sharp peaks at 26.54

$310(14 \%), 38.34(100 \%)$ and $44.59(86 \%) 2 \theta$. The characteristic peaks of cellulose do not change in the

311 spectra, indicating that the crystallinity and fibrous structure of the cellulose are not damaged as a

312 consequence of the chemical interaction between cellulose and maleic acid, as indicated above. This

313 indicates that esterification occurs in the amorphous structure of cellulose, not in the crystalline component. 
This is a peer-reviewed, accepted author manuscript of the following chapter: Fletcher, A., Hashem, A., Farag, S., Taha, G., Badawy, S., \& Mohamed, L. (Accepted/In press). Non-linear adsorption characteristics of modified pine wood sawdust optimised for adsorption of Cd(II) from aqueous systems. Journal of Environmental Chemical Engineering.
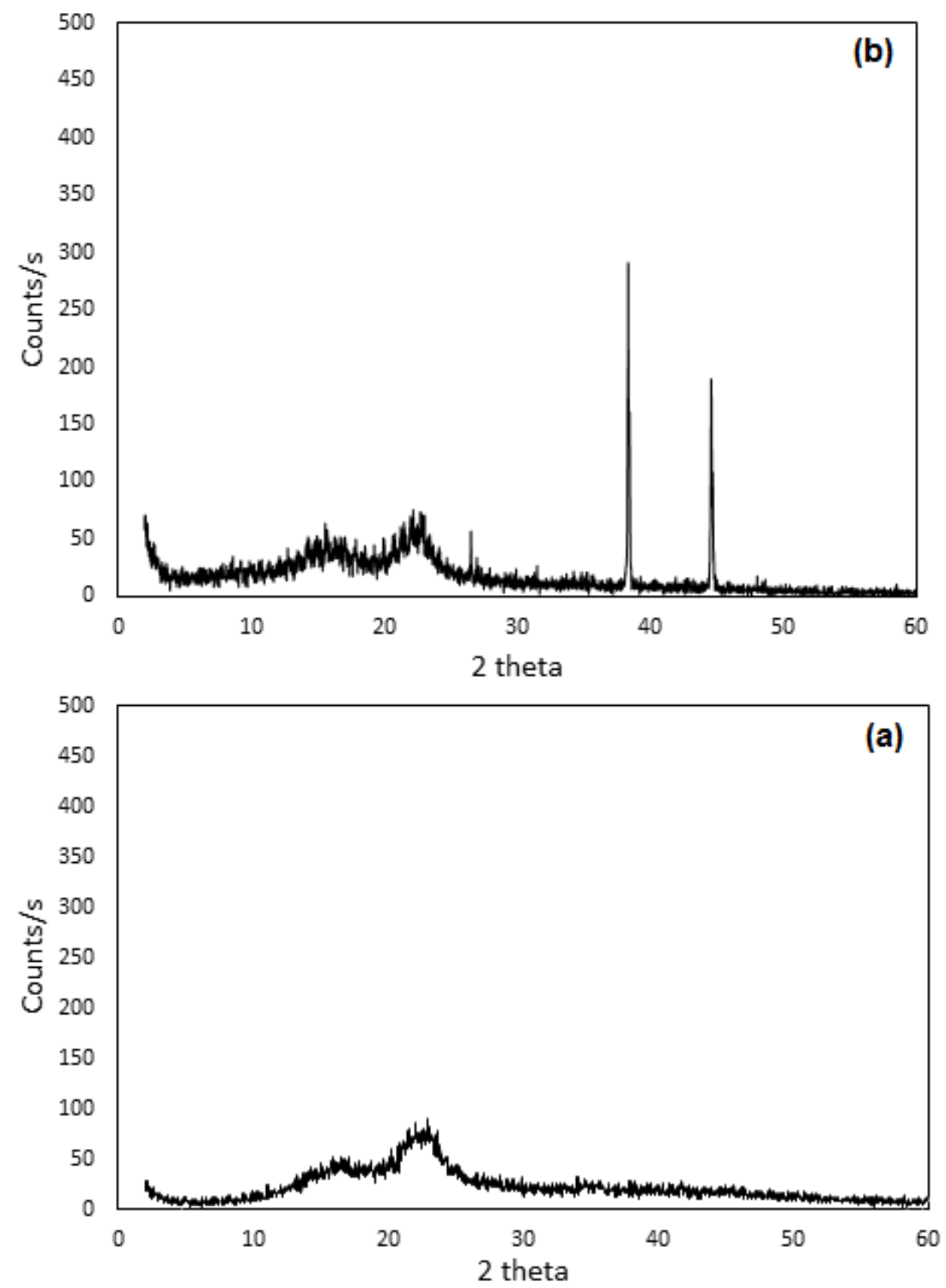

316 Figure 4:X-ray diffraction spectra of (a) pine wood sawdust (SD) and (b) pinewood sawdust treated with maleic 317 acid SDTMA. 
This is a peer-reviewed, accepted author manuscript of the following chapter: Fletcher, A., Hashem, A., Farag, S., Taha, G., Badawy, S., \& Mohamed, L. (Accepted/In press). Non-linear adsorption characteristics of modified pine wood sawdust optimised for adsorption of $\mathrm{Cd}(\mathrm{II})$ from aqueous systems. Journal of Environmental Chemical Engineering.<smiles>O=C(O)C=CC(=O)O</smiles>

Maleic acid<smiles>O=C1C=CC(=O)O1</smiles>

Maleic anhydride<smiles>CCCC</smiles>

Maleic anhydride<smiles></smiles>

SD<smiles>O=C(O)/C=C\C(=O)OC1CCCCC1</smiles>

SDTMA hydrogen bond is destructed compared to the intramolecular hydrogen bond [45, 46].

Scheme1: Reaction of pinewood sawdust (SD) with maleic acid (MA) to form pinewood sawdust treated with maleic acid (SDTMA) at high temperature.

In this study, the presence of maleic acid (MA) under a high reaction temperature would allow the formation of maleic anhydride (MAA), which may react with the cellulosic hydroxyls of SD, during such heating, to form sawdust functionalised with maleic acid (SDTMA) as obtained in this study. The proposed reaction pathway is shown in Scheme 1.

The reaction mechanisms for cellulose with maleic acid to form a bond through carboxyl group was described in figure 1 .The maleic anhydride may react partially with wood, when a single ester function and a free carboxylic group result, or completely to form di-ester structures [44]. The hydroxyl groups at C-2, C-3 and C-6 of cellulose are reactive and can react with anhydride. The intensity of the peak at $3322 \mathrm{~cm}^{-1}$ reduced obviously, indicating that more intermolecular 
This is a peer-reviewed, accepted author manuscript of the following chapter: Fletcher, A., Hashem, A., Farag, S., Taha, G., Badawy, S., \& Mohamed, L. (Accepted/In press). Non-linear adsorption characteristics of modified pine wood sawdust optimised for adsorption of Cd(II) from aqueous systems. Journal of Environmental Chemical Engineering.

\subsection{Influence of reaction parameters on SDTMA carboxyl content}

335

336

344

\subsubsection{Effect of maleic acid concentration}

Figure 5 shows the effect MA concentration on the extent of functional group incorporation, expressed as m.eq.-COOH $100 \mathrm{~g}^{-1}$ SDTMA, for treatment of SD particles with different concentrations of MA. There is, as expected, an increase in carboxyl group concentration, 71.7 to 234.6 m.eq. $100 \mathrm{~g}^{-1}$ SDTMAwith increasing MA concentration (4.3 to $69 \mathrm{mmol} \mathrm{L}^{-1}$ ), the observed trend is an initial sharp increase with an approach to a plateau at higher MA concentration. As the availability of maleic acid molecules in contact with the SD increases, this results in increasing carboxyl content by reaction with the hydroxyl groups present in the parent material, after which carboxyl groups are converted to anhydride groups by dehydration at higher temperatures.

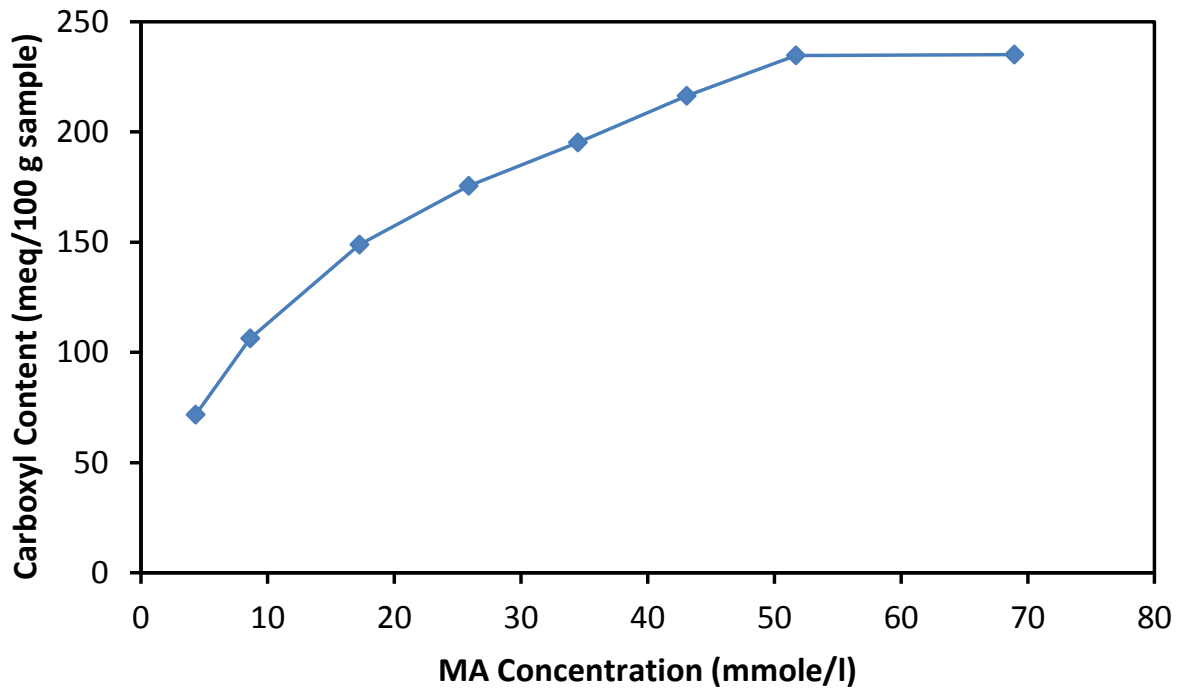

Figure 5: Effect of maleic acid concentration on the extent of modification of pinewood sawdust treated with maleic acid. Reaction conditions: sawdust mass: $2 \mathrm{~g}$; particle size range: 50- $125 \mu \mathrm{m}$; reaction temperature: $413 \mathrm{~K}$; reaction time: $1 \mathrm{~h}$; carboxyl content: $247 \mathrm{~m} . e q .100 \mathrm{~g}^{-1}$ sample.

\subsubsection{Effect of reaction temperature}

Figure 6 presents the results obtained from experiments to study the effect of reaction temperature on the extent of chemical modification of SD particles treated with MA. Carboxyl content increases from 200.8 to 247.2 m.eq. $100 \mathrm{~g}^{-1} \mathrm{~S}$ DTMA as reaction temperature increases from 373 to $403 \mathrm{~K}$; 
This is a peer-reviewed, accepted author manuscript of the following chapter: Fletcher, A., Hashem, A., Farag, S., Taha, G., Badawy, S., \& Mohamed, L. (Accepted/In press). Non-linear adsorption characteristics of modified pine wood sawdust optimised for adsorption of Cd(II) from aqueous systems. Journal of Environmental Chemical Engineering.

353

354

355

\section{8}

subsequent increase in temperature, above $403 \mathrm{~K}$, results in a decrease in carboxyl content after the maximum is achieved. It is likely that the carboxyl content of SDTMA is enhanced by increasing the reaction temperature to $403 \mathrm{~K}$, as both (1) conversion of MA to MAA and (2) reaction of MAA with cellulosic hydroxyls of SD particles are favoured by higher temperatures. On the other hand, SDTMA is decarboxylated at temperatures higher than $403 \mathrm{~K}$.

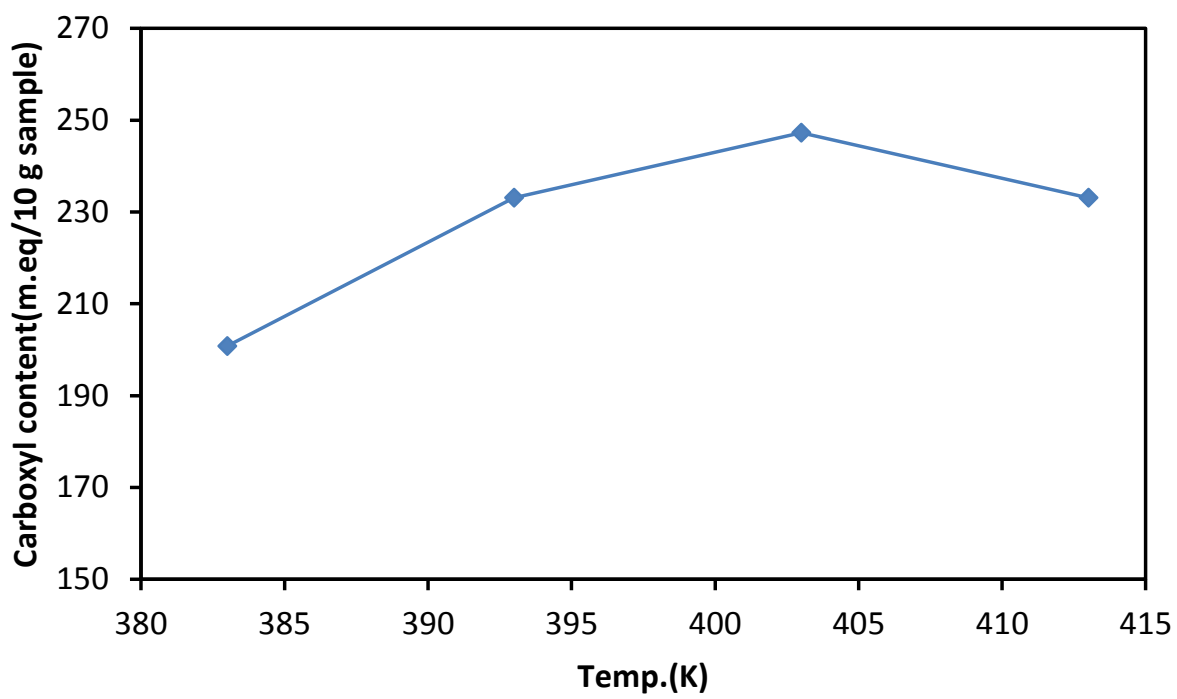

Figure 6: Effect of dehydration temperature on the extent of modification of pinewood sawdust treated with maleic acid. Reaction conditions: sawdust mass: $2 \mathrm{~g}$; particle size range: 50- $125 \mu \mathrm{m}$; maleic acid concentration: $51.7 \mathrm{mmol} \mathrm{L}^{-1}$; reaction time: $1 \mathrm{~h}$; carboxyl content: 247 m.eq. $100 \mathrm{~g}^{-1}$ sample.

\subsubsection{Effect of reaction time}

Figure 7 shows the variation in carboxyl content of SDTMA with changing reaction time. The carboxyl content of SDTMA increases from 225.4 to 242.9 m.eq. $100 \mathrm{~g}^{-1}$ SDTMAas reaction time increases from 30 to $60 \mathrm{~min}$, before a subsequent decrease is observed at higher reaction times. It is evident that increased time results in increased formation of MAA, which reacts with cellulosic hydroxyl groups to form the carboxyl functionalities observed in the final product of SDTMA. Further time within the reaction system results in catalytic effects on the carboxyl groups and their concentration is decreased, resulting in a final value of $210.71 \mathrm{~m}$.eq. $100 \mathrm{~g}^{-1}$ SDTMAobserved at300 min [47]. 
This is a peer-reviewed, accepted author manuscript of the following chapter: Fletcher, A., Hashem, A., Farag, S., Taha, G., Badawy, S., \& Mohamed, L. (Accepted/In press). Non-linear adsorption characteristics of modified pine wood sawdust optimised for adsorption of Cd(II) from aqueous systems. Journal of Environmental Chemical Engineering.

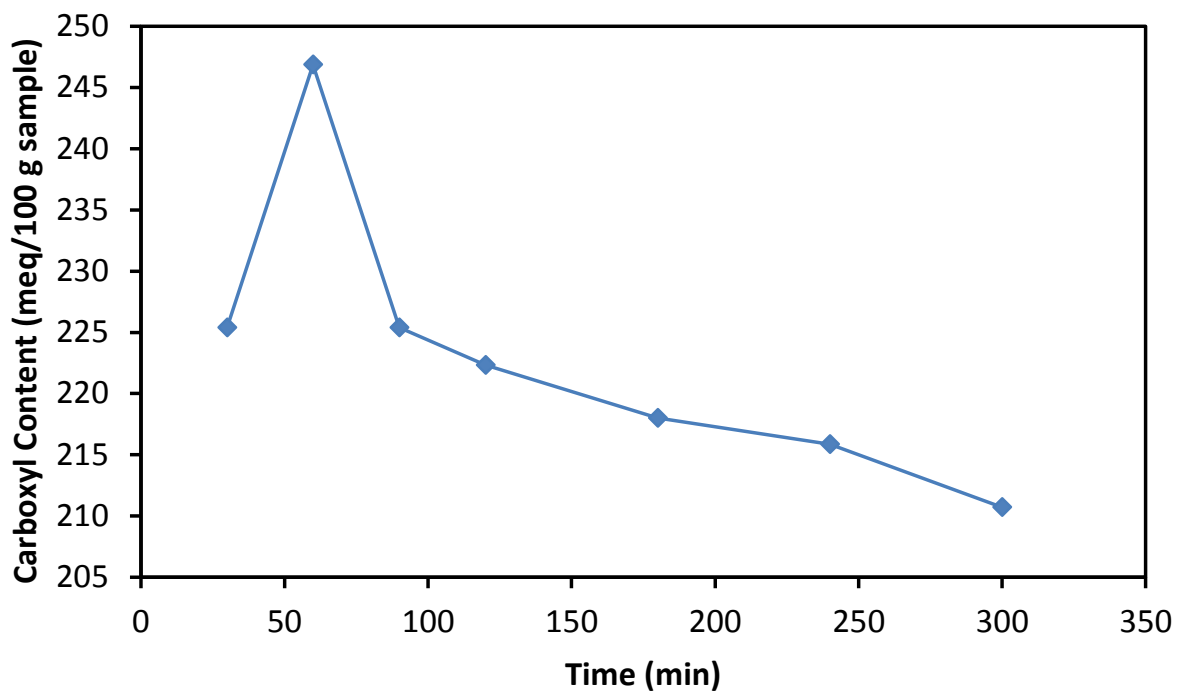

Figure 7: Effect of reaction time on the extent of modification of pinewood sawdust treated with maleic acid. Reaction conditions: sawdust mass: $2 \mathrm{~g}$; particle size range: 50- $125 \mu \mathrm{m}$; maleic acid concentration: $51.7 \mathrm{mmol} \mathrm{L}^{-1}$; reaction temperature $403 \mathrm{~K}$; carboxyl content: 247 m.eq. $100 \mathrm{~g}^{-1}$ sample.

\subsection{Factors affecting adsorption of Cd(II) onto SDTMA}

\subsubsection{Point of zero charge $\left(\mathrm{pH}_{p z c}\right)$ and effect of $\mathrm{pH}$}

The results of studies into the effect of $\mathrm{pH}$ on the adsorption of $\mathrm{Cd}(\mathrm{II})$ ions by SDTMA, in the range $\mathrm{pH}$ $\mathrm{Cd}(\mathrm{II})$ increased from 23 to $136 \mathrm{mg} \mathrm{g}^{-1}$ with increasing $\mathrm{pH}$, up to 6 , before a plateau is achieved at higher $\mathrm{pH}$. This increase is attributed to ion-exchange processes:

$$
\begin{aligned}
& \text { 2SDTMA-COOH } \leftrightarrow 2 \text { SDTMA-COO }^{-}+2 \mathrm{H}^{+} \\
& \text {2SDTMA-COO }+\mathrm{M}^{2+} \leftrightarrow\left(\text { SDTMA-COO }_{2} \mathrm{M}\right.
\end{aligned}
$$

Deprotonation of SDTMA, the first stage in ion exchange, is shown in Equation 4; the products of which offer adsorption sites for the $\mathrm{Cd}(\mathrm{II})$ ions (Equation 5). As can be seen from Figure 8, the adsorption capacity $\left(\mathrm{q}_{\mathrm{e}}\right)$ of SDTMA towards $\mathrm{Cd}(\mathrm{II})$ ions was zero at $\mathrm{pH} 3$, as the presence of a higher concentration of protons causes the equilibrium in Equation 4 to shift to the left, favouring the protonated version of SDTMA and reducing the sites available for Cd(II) ion adsorption. The number of deprotonated sites 
This is a peer-reviewed, accepted author manuscript of the following chapter: Fletcher, A., Hashem, A., Farag, S., Taha, G., Badawy, S., \& Mohamed, L. (Accepted/In press). Non-linear adsorption characteristics of modified pine wood sawdust optimised for adsorption of $\mathrm{Cd}(\mathrm{II})$ from aqueous systems. Journal of Environmental Chemical Engineering.

subsequently increases as the $\mathrm{pH}$ becomes less acidic, with a maximum at $\mathrm{pH} 6$. After this point the uptake decreases again, as there is a significant precipitation reaction of cadmium as hydroxide.

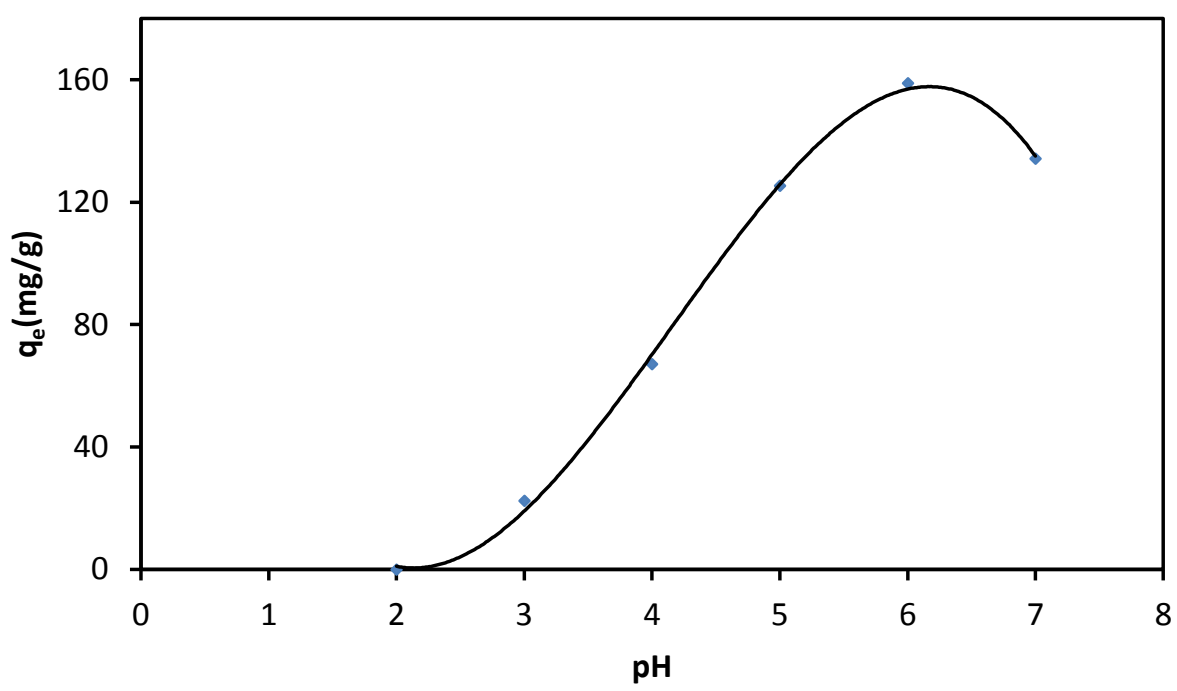

Figure 8: Effect of solution $\mathrm{pH}$ on adsorption capacity of pinewood sawdust treated with maleic acid (SDTMA) for $\mathrm{Cd}(\mathrm{II})$ ions. Reaction conditions: adsorptive concentration: $300 \mathrm{mg} \mathrm{L}^{-1}$; adsorbent dose: $0.3 \mathrm{~g} \mathrm{~L}^{-1}$; particle size range: 50-125; contact time: $2 \mathrm{~h}$; adsorption temperature, $403 \mathrm{~K}$.

Figure 9 shows the $\mathrm{pH}_{p z c}$ data obtained for the surface of SDTMA, which allows the $\mathrm{pH}$ at which the surface of SDTMA has neutral charge to be determined. At solution pHs higher than this point of neutrality, the surface will be on the whole negatively charged, likewise, the surface will be positively charged in the main at solution $\mathrm{pHs}$ lower than $\mathrm{pH}_{p z c}$ [48]. Additionally, $\mathrm{pH}_{p z c}$ provides an indication of the electrostatic interactions that occur between the adsorbent surface and the adsorbate [49].The $\mathrm{pH}_{p z c}$ of SDTMA was determined as 4, which indicates an acidic nature for the surface of SDTMA. As aforementioned, higher $\mathrm{pH}$ values will result in a negative charge on the surface of SDTMA, which favours the binding of cations; conversely, lower $\mathrm{pH}$ values will cause a positively charged surface, which makes the adsorption of cations unfavourable [50]. 
This is a peer-reviewed, accepted author manuscript of the following chapter: Fletcher, A., Hashem, A., Farag, S., Taha, G., Badawy, S., \& Mohamed, L. (Accepted/In press). Non-linear adsorption characteristics of modified pine wood sawdust optimised for adsorption of $\mathrm{Cd}(\mathrm{II})$ from aqueous systems. Journal of Environmental Chemical Engineering.

403

404

405

As stated in the previous section, the optimum $\mathrm{pH}$ for SDTMA to adsorb $\mathrm{Cd}(\mathrm{II})$ from solution is 6 , which

is higher than $\mathrm{pH}_{p z c}$, and leads to a predominantly negative surface charge on the adsorbent surface,

resulting in electrostatic attraction with the positively charged $\mathrm{Cd}(\mathrm{II})$ cations [51].

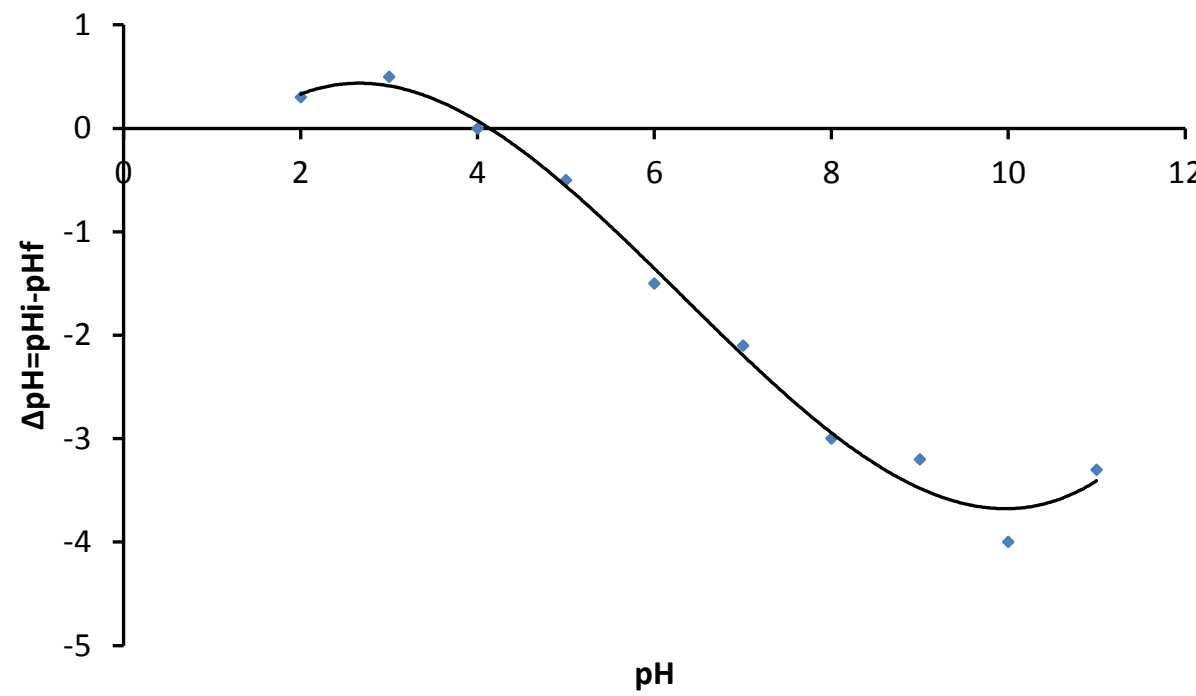

406

407

Figure 9: Point of zero charge (PZC) for pinewood sawdust treated with maleic acid (SDTMA).

408

409

\subsubsection{Effect of contact time}

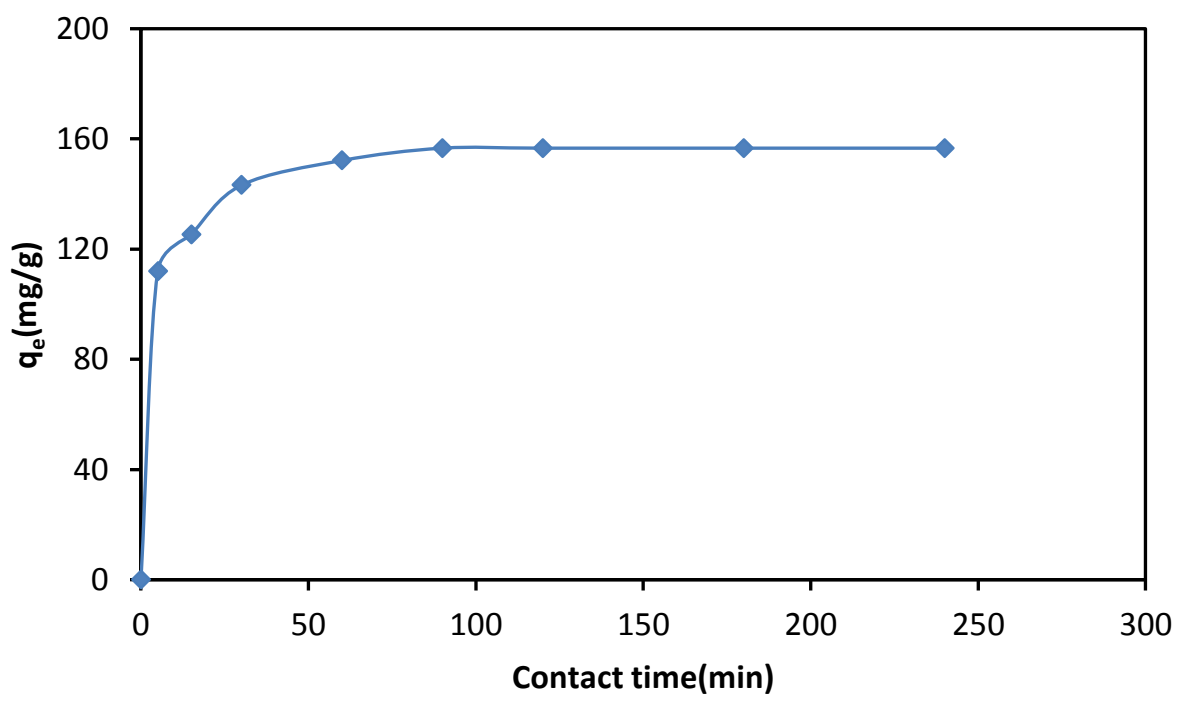

Figure 10: Effect of contact time on adsorption capacity of $\mathrm{Cd}(\mathrm{II})$ ions on pinewood sawdust treated with maleic acid (SDTMA). Reaction conditions: adsorptive concentration: $300 \mathrm{mg} \mathrm{L}^{-1}$; adsorbent dose $0.3 \mathrm{~g} \mathrm{~L}^{-1}$; 
This is a peer-reviewed, accepted author manuscript of the following chapter: Fletcher, A., Hashem, A., Farag, S., Taha, G., Badawy, S., \& Mohamed, L. (Accepted/In press). Non-linear adsorption characteristics of modified pine wood sawdust optimised for adsorption of $\mathrm{Cd}(\mathrm{II})$ from aqueous systems. Journal of Environmental Chemical Engineering.

415 The effect of adsorption contact time on the capacity of SDTMA towards Cd(II) ions, at an initial 416 adsorptive concentration of $200 \mathrm{mg} \mathrm{L}^{-1}$, is shown in Figure 10. The capacity of SDTMA to adsorb Cd(II)

417 ions increased with increasing contact time, up to an equilibrium at $45 \mathrm{~min}$, after which a plateau is 418 observed and no further improvement is achieved. This equilibrium time is relatively short [52], which 419 is an important consideration in the development of an economically viable wastewater treatment system.

\subsubsection{Effect of adsorbent dose}

423 It has been previously observed, in many studies, that adsorbent dose influences the uptake of target 424 species from solution, including metal ions. The effect of adsorbent dose on the adsorption capacity 425 of SDTMA for $\mathrm{Cd}(\mathrm{II})$ ions was studied at $\mathrm{pH} 6$, using adsorbent doses in the range $0.5-8 \mathrm{~g} \mathrm{~L}^{-1}$, and an 426 initial metal ion concentration of $200 \mathrm{mg} \mathrm{L}^{-1}$ (Figure 11). It can be seen that the adsorption capacity $427\left(\mathrm{q}_{\mathrm{e}}\right)$ of $\mathrm{Cd}(\mathrm{II})$ ions, per gram of adsorbent $\left(\mathrm{mg} \mathrm{g}^{-1}\right)$, decreased from 157.1 to $48 \mathrm{mg} \mathrm{g}^{-1}$ with increasing 428 adsorbent dose, up to $7 \mathrm{~g} \mathrm{~L}^{-1}$. With increasing the adsorbent dose, increasing of unsaturated 429 adsorption sites take places, as a result a decrease per unit mass and adsorption capacity of SDTMA for $\mathrm{Cd}(\mathrm{II})$ ions decreases, as has been observed previously for $\mathrm{Zn}(\mathrm{II})[9]$. 
This is a peer-reviewed, accepted author manuscript of the following chapter: Fletcher, A., Hashem, A., Farag, S., Taha, G., Badawy, S., \& Mohamed, L. (Accepted/In press). Non-linear adsorption characteristics of modified pine wood sawdust optimised for adsorption of Cd(II) from aqueous systems. Journal of Environmental Chemical Engineering.

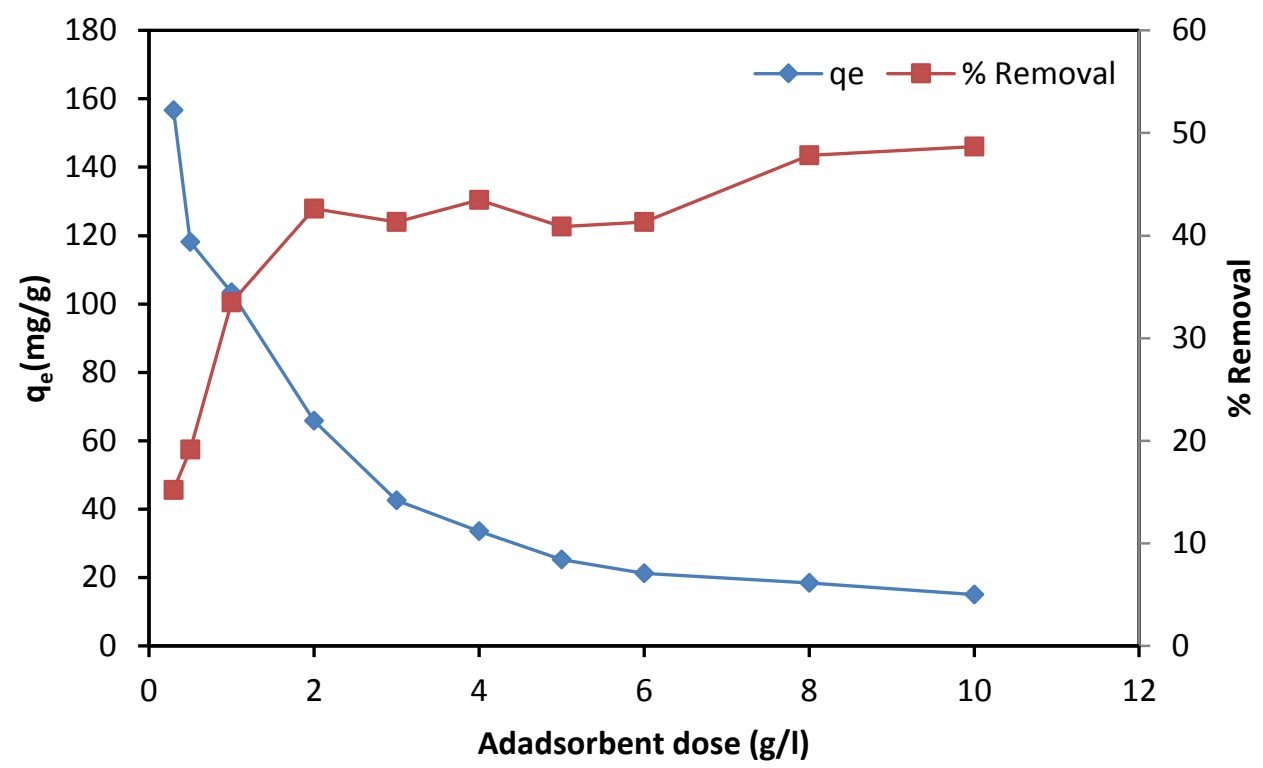

431 model, was $180.4 \mathrm{mg} \mathrm{g}^{-1}$. Table 2 shows that the SDTMA produced within the present work has

Figure 11: Effect of adsorbent dose ( $\mathrm{g} / \mathrm{l}$ ) on adsorption capacity (LHS) and percentage removal (RHS) of Cd(II) ions on pinewood sawdust treated with maleic acid (SDTMA). Reaction conditions: adsorptive concentration: $300 \mathrm{mg} \mathrm{L}^{-1}$; particle size range, 50-125; $\mathrm{pH}$ : 6; contact time: $2 \mathrm{~h}$; adsorption temperature, $403 \mathrm{~K}$.

\subsection{Isothermal analysis of Cd(II) ion adsorption on SDTMA}

An adsorption isotherm describes the thermodynamic equilibrium established between the amount adsorbed on the adsorbent surface with the amount of adsorptive remaining in solution. Several models have been developed to describe the behaviour that may be observed in adsorption systems, and a range of those based on two or three parameters are used to analyse the data obtained in this study, including the two-parameter models of Langmuir, Temkin, Freundlich, and DubininRadushkevich (D-R), and the three-parameter models of Sips, Redlich-Peterson (R-P), Toth and Khan. The isothermal data analysed was obtained for adsorption of $\mathrm{Cd}(\mathrm{II})$ ions onto SDTMA, at pH 6, allowing an equilibrium time of $60 \mathrm{~min}$.

The maximum adsorption capacity for $\mathrm{Cd}(\mathrm{II})$ ions onto SDTMA, according to the Langmuir isotherm a high affinity for the removal of Cd(II) ions (180 mg/g) from solution when compared with 
This is a peer-reviewed, accepted author manuscript of the following chapter: Fletcher, A., Hashem, A., Farag, S., Taha, G., Badawy, S., \& Mohamed, L. (Accepted/In press). Non-linear adsorption characteristics of modified pine wood sawdust optimised for adsorption of $\mathrm{Cd}(\mathrm{II})$ from aqueous systems. Journal of Environmental Chemical Engineering.

449

wood sawdust raw materials $(41 \mathrm{mg} / \mathrm{g})$ and other various adsorbents previously reported in the literature [42, 53-62].

Table 2: Comparison of adsorption capacities of various adsorbents for $\mathrm{Cd}(\mathrm{II})$

\begin{tabular}{|c|c|c|}
\hline Adsorbent & $\begin{array}{c}\text { Adsorption capacity } \\
\left(\mathrm{mg} \mathrm{g}^{-1}\right)\end{array}$ & References \\
\hline Thiol-functionalized magnetic sawdust & 4 & 52 \\
\hline Sawdust grafted with acrylic acid(carboxyl) & 168 & 54 \\
\hline Wood pulpgrafted with acrylic acid(carboxyl) & 4 & 55 \\
\hline Zeolites Clinoptilolite & 3.7 & 56 \\
\hline Zeolites Scolecite & 70 & 57 \\
\hline Organophilic bentoniteClays & 2.8 & 59 \\
\hline Biomass P. chrysosporium & 27.8 & 60 \\
\hline PET was grafted with (2-HPMA) & 18.87 & 61 \\
\hline Coffee grounds waste & 15.65 & 62 \\
\hline Phosphogypsum waste & 131.58 & Present study \\
\hline Wood sawdust & 41.21 & 180.4 \\
\hline Sawdust treated maleic acid & & 58 \\
\hline
\end{tabular}

Figure 12 shows a comparison between the experimental isothermal data obtained in this study and

the theoretical fits offered by the different two- and three-parameter isotherm models described above. Additionally, Tables 3 and 4 present the error analysis and constants for the isotherm models used here. Isotherm type is determined by the value of $R_{L}$ determined from the Langmuir model data; irreversible when $R_{L}=0$, favourable for $0<R_{L}<1$, linear if $R_{L}=1$, or unfavourable in the case of $R_{L}>1$. The calculated factor of dimensionless separation for $C d(I I)$ ions onto SDTMA is 0.28 , while $R_{L}$ was greater than zero but less than 1 , therefore, indicating favourable adsorption.

The value of $n$ in the Freundlich model (Table 3) was 4.18, satisfying $0<n<10$, which also indicates that adsorption of $\mathrm{Cd}(\mathrm{II})$ ions onto SDTMA is favourable. The value of $1 / \mathrm{n}<1$ suggests a slight suppression of adsorption at lower equilibrium concentrations. 
This is a peer-reviewed, accepted author manuscript of the following chapter: Fletcher, A., Hashem, A., Farag, S., Taha, G., Badawy, S., \& Mohamed, L. (Accepted/In press). Non-linear adsorption characteristics of modified pine wood sawdust optimised for adsorption of Cd(II) from aqueous systems. Journal of Environmental Chemical Engineering.

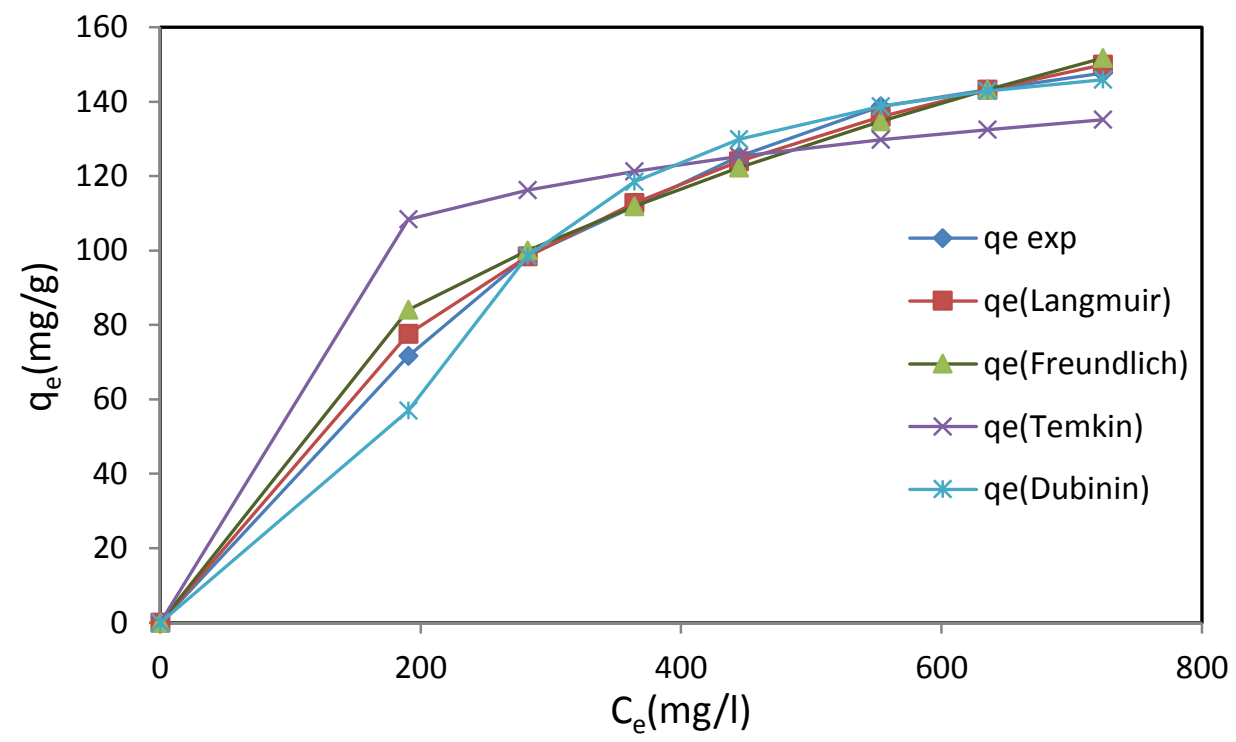

Figure 12: Comparison of data obtained experimentally for adsorption of $\mathrm{Cd}(\mathrm{II})$ ions onto pinewood sawdust treated with maleic acid (SWTMA) and two parameter isothermal models used to analyse the data.

Table 3 shows that the two-parameter isotherm models are ordered, in terms of best fit to the experimental data, as: Langmuir> Freundlich > Dubinin-Radushkevich> Temkin; while Table 4 shows that the three-parameter isotherm models were determined to be in the order: Sips $>$ Khan $>$ Toth $>$ Redlich-Peterson, for the best fit to the data. As may be expected from the increase if fitting variables, the three-parameter models were consistently found to provide a better fit to the experimental data than two-parameter models. Overall, the eight isotherm models can be presented in the following order of fitness, based on the correlation coefficient $\left(R^{2}\right)$ and error functions used in this study: Sips > Khan $>$ Toth $>$ Redlich-Peterson $>$ Langmuir $>$ Freundlich $>$ Dubinin-Radushkevich $>$ Temkin. The data were best fitted to Sips isotherm model. As this trend suggests, from all of the models used for analysis of the experimental data, the Sips isotherm model gave the highest $R^{2}$ value, as well as the lowest ARE, APE $\%, \chi^{2}$ and HYBRID error functions values, indicating that it gave the best overall fit to the data explaining the equilibrium adsorption of Cd (II) onto SDTMA (Figures 12 and 13).

This model is a combined of Langmuir and Freundlich expressions developed to predict the heterogeneous adsorption systems. Therefore at low adsorbate concentration, $\beta=0$, this model 
This is a peer-reviewed, accepted author manuscript of the following chapter: Fletcher, A., Hashem, A., Farag, S., Taha, G., Badawy, S., \& Mohamed, L. (Accepted/In press). Non-linear adsorption characteristics of modified pine wood sawdust optimised for adsorption of $\mathrm{Cd}(\mathrm{II})$ from aqueous systems. Journal of Environmental Chemical Engineering.

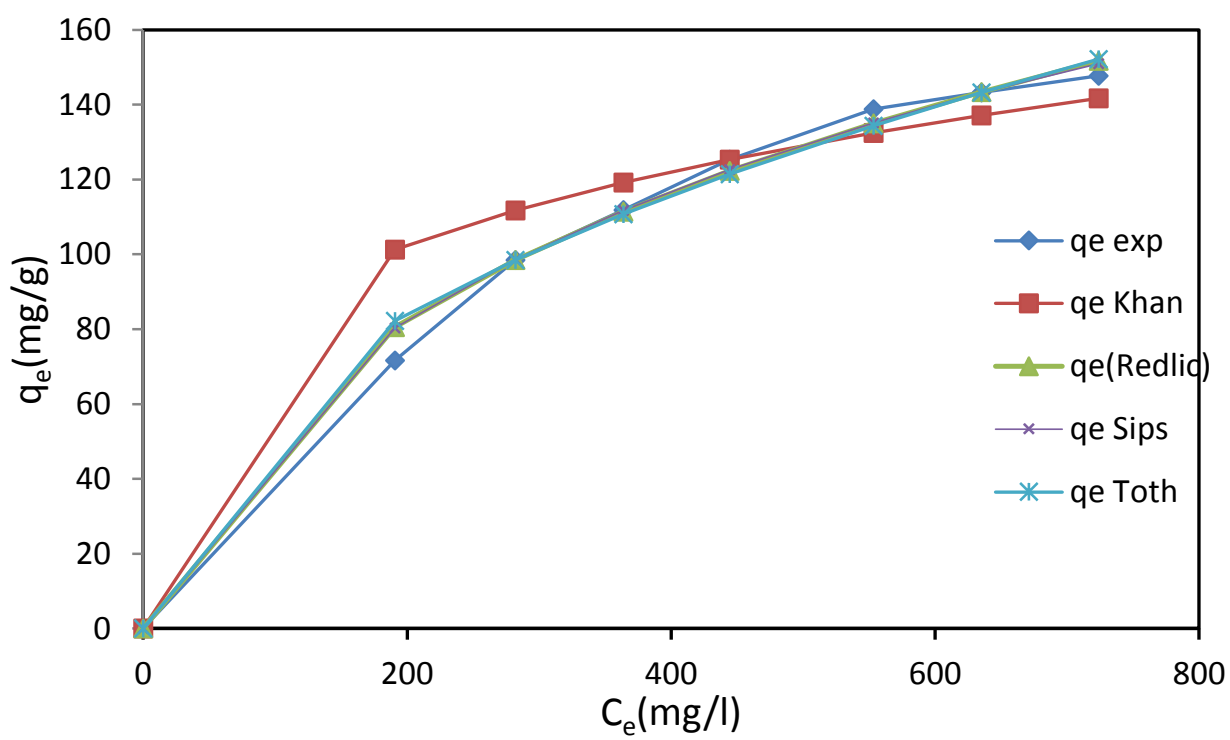

Figure 13: Comparison of data obtained experimentally for adsorption of $\mathrm{Cd}(\mathrm{II})$ ions onto pinewood sawdust treated with maleic acid (SWTMA) and three-parameter isothermal models used to analyse the data

Table 3: Isotherm constants of two-parameter models for $\mathrm{Cd}(\mathrm{II})$ ions adsorption onto SDTMA at $303 \mathrm{~K}$

\begin{tabular}{|c|c|c|c|c|}
\hline Isotherm Model & Parameter & Value & Error Analysis & Value \\
\hline \multirow{5}{*}{ Langmuir } & $a_{\mathrm{L}}$ & 0.002756 & ARE & 0.1369 \\
\hline & $\mathrm{R}_{\mathrm{L}}$ & 0.276 & APE\% & 1.9554 \\
\hline & $\mathrm{kL}_{\mathrm{L}}$ & 0.620304 & Hybrid & 0.6010 \\
\hline & \multirow[t]{2}{*}{$Q_{\max }$} & \multirow[t]{2}{*}{225.0379} & $\mathrm{R}^{2}$ & 0.9995 \\
\hline & & & $\chi^{2}$ & 9.9526 \\
\hline \multirow[t]{5}{*}{ Freundlich } & $\mathrm{n}$ & 2.256288 & ARE & 0.2691 \\
\hline & \multirow{4}{*}{$\mathrm{K}_{\mathrm{F}}$} & \multirow{4}{*}{8.199321} & APE\% & 3.8450 \\
\hline & & & Hybrid & 2.4764 \\
\hline & & & $\mathbf{R}^{2}$ & 0.9980 \\
\hline & & & $\chi^{2}$ & 18.5262 \\
\hline \multirow[t]{5}{*}{ Temkin } & $\mathrm{A}_{\mathrm{T}}$ & 1.154914 & ARE & 1.0020 \\
\hline & \multirow{4}{*}{$\mathrm{b}_{\text {T }}$} & \multirow{4}{*}{125.4493} & APE\% & 14.3143 \\
\hline & & & Hybrid & 25.2684 \\
\hline & & & $\mathbf{R}^{2}$ & 0.9787 \\
\hline & & & $\chi^{2}$ & 73.1503 \\
\hline \multirow[t]{5}{*}{ Dubinin-Radushkevich } & $\mathrm{q}_{\mathrm{D}}$ & 156.5302 & ARE & 0.3156 \\
\hline & \multirow{4}{*}{$\mathrm{BD}_{\mathrm{D}}$} & \multirow{4}{*}{14.67483} & APE\% & 4.5083 \\
\hline & & & Hybrid & 3.5906 \\
\hline & & & $\mathbf{R}^{2}$ & 0.9973 \\
\hline & & & $\chi^{2}$ & 20.4253 \\
\hline
\end{tabular}


This is a peer-reviewed, accepted author manuscript of the following chapter: Fletcher, A., Hashem, A., Farag, S., Taha, G., Badawy, S., \& Mohamed, L. (Accepted/In press). Non-linear adsorption characteristics of modified pine wood sawdust optimised for adsorption of $\mathrm{Cd}(\mathrm{II})$ from aqueous systems. Journal of Environmental Chemical Engineering.

Table 4: Isotherm constants of three-parameter models for $\mathrm{Cd}(\mathrm{II})$ ions adsorption onto SDTMA at $303 \mathrm{~K}$

\begin{tabular}{|c|c|c|c|c|}
\hline Isotherm Model & Parameter & Value & Error Analysis & Value \\
\hline \multirow{5}{*}{ Redlich-Peterson } & $\mathrm{kg}$ & 1.379004 & ARE & 0.2093 \\
\hline & $\alpha_{R}$ & 0.064915 & APE\% & 2.9897 \\
\hline & \multirow{3}{*}{$g$} & \multirow[t]{3}{*}{0.676384} & Hybrid & 1.4088 \\
\hline & & & $\mathbf{R}^{2}$ & 0.9988 \\
\hline & & & $\chi^{2}$ & 15.4557 \\
\hline \multirow{5}{*}{ Toth } & $\mathrm{kt}_{\mathrm{t}}$ & 7.289696 & ARE & 0.2500 \\
\hline & $a_{t}$ & 0.08939 & APE\% & 3.5716 \\
\hline & \multirow[t]{3}{*}{$1 / \mathrm{t}$} & \multirow[t]{3}{*}{0.538547} & Hybrid & 1.9627 \\
\hline & & & $\mathbf{R}^{2}$ & 0.9983 \\
\hline & & & $\chi^{2}$ & 18.4182 \\
\hline \multirow{5}{*}{ Sips } & $\mathrm{K}_{\mathrm{s}}$ & 2.567092 & ARE & 0.1944 \\
\hline & $a_{s}$ & 0.007467 & APE\% & 2.7770 \\
\hline & \multirow{3}{*}{$\mathrm{B}_{\mathrm{s}}$} & \multirow{3}{*}{0.706641} & Hybrid & 1.2952 \\
\hline & & & $\mathbf{R}^{2}$ & 0.9989 \\
\hline & & & $\chi^{2}$ & 13.9028 \\
\hline \multirow{5}{*}{ Khan } & $Q_{\max }$ & 191.43 & ARE & 0.74147 \\
\hline & $a_{k}$ & 1 & APE\% & 10.5924 \\
\hline & \multirow{3}{*}{$b_{k}$} & \multirow{3}{*}{0.004389} & Hybrid & 15.2881 \\
\hline & & & $R^{2}$ & 0.9879 \\
\hline & & & $\chi^{2}$ & 51.1072 \\
\hline
\end{tabular}

494 
This is a peer-reviewed, accepted author manuscript of the following chapter: Fletcher, A., Hashem, A., Farag, S., Taha, G., Badawy, S., \& Mohamed, L. (Accepted/In press). Non-linear adsorption characteristics of modified pine wood sawdust optimised for adsorption of $\mathrm{Cd}(\mathrm{II})$ from aqueous systems. Journal of Environmental Chemical Engineering.

496

497

498

499

500

501

502

503

504

505

506

507

508

509

\subsection{Adsorption kinetics}

In addition to studying the equilibrium behaviour of adsorption systems, it is critical to understand their approach to this equilibrium by also studying the kinetics of adsorption, which can provide insight into the mechanism of adsorption. In this work, five models were used to model the kinetics of Cd(II)adsorption onto SDTMA: pseudo-first-order, pseudo second-order, Bangham, Elovich. The intraparticle diffusion model is not appropriate for studies at high adsorption times. To understand the adsorption mass transfer, the use of approximated models like Weber-Morris (intraparticle diffusion model), is not recommended. Weber-Morris is only valid for short adsorption times and when the bulk concentration is little affect. The Kinetic parameters calculated for this study and normalized standard deviation $(\Delta \mathrm{q}(\%))$ for adsorption of $\mathrm{Cd}(\mathrm{II})$ ions onto SDTMA at $303 \mathrm{~K}$ are summarised in Table 5.

Table 5: Kinetic parameters and normalized standard deviation $(\Delta q(\%))$ for adsorption of Cd (II) ions onto SDTMA at $303 \mathrm{~K}$

\begin{tabular}{|c|c|c|}
\hline \multirow[t]{2}{*}{ Models } & \multirow{2}{*}{ Parameters } & Values \\
\hline & & $(300 \mathrm{mg} / \mathrm{l})$ \\
\hline \multirow{4}{*}{ Pseudo-first order } & $\mathrm{k}_{1}$ & 0.1073 \\
\hline & $\mathrm{q}_{\mathrm{e}}$ & 156.6542 \\
\hline & $\mathrm{R}^{2}$ & 0.9866 \\
\hline & $\Delta q(\%)$ & 14.8043 \\
\hline \multirow{4}{*}{ Pseudo-second order } & $\mathrm{K}_{2}$ & 0.0031 \\
\hline & $q_{e}$ & 157.9997 \\
\hline & $\mathrm{R}^{2}$ & 0.9987 \\
\hline & $\Delta q(\%)$ & 0.0150 \\
\hline \multirow{5}{*}{ Bangham's Equation } & $q_{e}$ & 150.4382 \\
\hline & $\mathrm{n}$ & 1.0910 \\
\hline & $\mathrm{K}_{\mathrm{b}}$ & 0.0933 \\
\hline & $\mathrm{R}^{2}$ & 0.9838 \\
\hline & $\Delta q(\%)$ & 15.5234 \\
\hline \multirow{4}{*}{ Elovich Equation } & $\alpha$ & 15 \\
\hline & $\beta$ & 0.03 \\
\hline & $\mathrm{R}^{2}$ & 0.867502 \\
\hline & $\Delta q(\%)$ & 26.81438169 \\
\hline
\end{tabular}


This is a peer-reviewed, accepted author manuscript of the following chapter: Fletcher, A., Hashem, A., Farag, S., Taha, G., Badawy, S., \& Mohamed, L. (Accepted/In press). Non-linear adsorption characteristics of modified pine wood sawdust optimised for adsorption of $\mathrm{Cd}(\mathrm{II})$ from aqueous systems. Journal of Environmental Chemical Engineering.

511 The highest $R^{2}$ and lowest $\Delta q \%$ values were obtained for the pseudo second-order kinetic model, and

512 indicate that this provides the best fit model to the experimental data for the kinetics of $\mathrm{Cd}(\mathrm{II})$

513 adsorption onto SDTMA (Figure 14), suggesting chemical control of the adsorption process. Overall,

514 the results obtained from the five kinetic models show that the adsorption kinetic models can be

515 ordered: pseudo second-order $>$ Bangham $>$ intra-particle $>$ pseudo first-order $>$ Elovich for the quality

516 of fit that they provide for the adsorption of $\mathrm{Cd}(\mathrm{II})$ ions onto SDTMA.

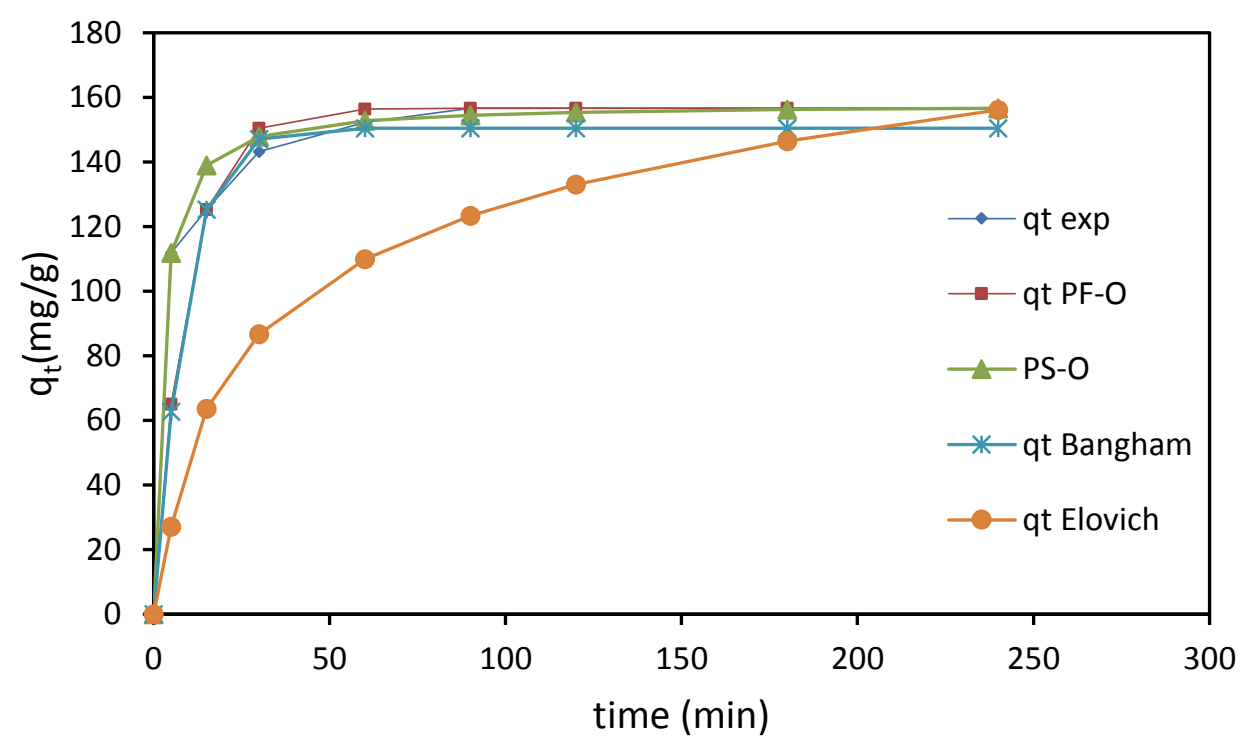

517

Figure 14: Comparison of data obtained experimentally for adsorption of $\mathrm{Cd}(\mathrm{II})$ ions onto pinewood sawdust treated with maleic acid (SWTMA) and kinetic models used to analyse the data.

520

521 It can be concluded that the adsorption process obeyed the pseudo-second-order kinetic model and

522 the adsorption isotherm followed sips isotherm equation, demonstrating that the adsorption process

523 of $\mathrm{Cd}(\mathrm{II})$ onto SDTMA is heterogeneous adsorption systems and dominated by the chemical 524 adsorption.

\subsection{Mechanism of adsorption}

The process of metal ion remediation from aqueous systems by agricultural adsorbents is still not fully understood due to the different interactions between the adsorbate and adsorbent, and the nature 
This is a peer-reviewed, accepted author manuscript of the following chapter: Fletcher, A., Hashem, A., Farag, S., Taha, G., Badawy, S., \& Mohamed, L. (Accepted/In press). Non-linear adsorption characteristics of modified pine wood sawdust optimised for adsorption of Cd(II) from aqueous systems. Journal of Environmental Chemical Engineering.

530

531

532

of the adsorbent structure. In this study, cadmium hydroxide $\mathrm{Cd}(\mathrm{OH})_{2}$ is the dominant form of the $\mathrm{Cd}(\mathrm{II})$ species in solution at $\mathrm{pH}>7$., while the dominant species at $\mathrm{pH}<7$ are $\mathrm{Cd}(\mathrm{OH})^{+}$and $\mathrm{Cd}^{2+}$ ions. The adsorption capacity is affected by the interaction of the adsorbent surface with these metal ion species. The highest adsorption capacity of SDTMA for $\mathrm{Cd}$ (II) ions was observed at $\mathrm{pH} 6$, which is close to the $\mathrm{pH}$ based on zeta potential analysis. Thus, the interaction of dominant species $\left(\mathrm{Cd}^{2+}\right.$ and $\left.\mathrm{Cd}(\mathrm{OH})^{+}\right)$ at $\mathrm{pH}<7$, with the functional groups on the SDTMA surface, leads to an enhanced adsorption capacity at this optimum $\mathrm{pH}$. The adsorption mechanism of porous adsorbents includes diffusion of ions to the external surface and into the pores of adsorbent, before ion exchange with the hydrogen ions associated with the carboxyl groups in SDTMA. The mechanism of $\mathrm{CD}(\mathrm{II})$ ion adsorption by SDTMA could also be due to complexation (Scheme 2), as well as physisorption and ion-exchange, and this may explain the results observed for adsorbent dosing, where increased accessibility of carboxyl groups from additional SDTMA may well increase the amount of complexation within the system.

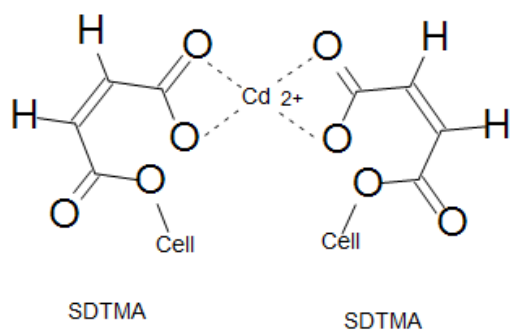

Scheme 2: The proposed complex structure formed between pinewood sawdust treated with maleic acid (SDTMA) and Cd(II) ions.

\section{Conclusions}

The adsorbent prepared within this study (SDTMA), formed via the treatment of pinewood sawdust (SD) with maleic acid, was used for the removal of $\mathrm{Cd}(\mathrm{II})$ ions from aqueous solutions. It was shown that the adsorption capacity of SDTMA was affected by adsorbent dose, $\mathrm{pH}$, contact time and metal ion concentration in solution. SD and SDTMA samples were analysed for morphological and chemical characteristics, showing a clear modification of the treated sample. The data obtained for adsorption of $\mathrm{Cd}(\mathrm{II})$ ions on SDTMA was analysed using a suite of two-parameter (Langmuir, Freundlich and 
This is a peer-reviewed, accepted author manuscript of the following chapter: Fletcher, A., Hashem, A., Farag, S., Taha, G., Badawy, S., \& Mohamed, L. (Accepted/In press). Non-linear adsorption characteristics of modified pine wood sawdust optimised for adsorption of $\mathrm{Cd}(\mathrm{II})$ from aqueous systems. Journal of Environmental Chemical Engineering.

553 Temkin, Dubinin-Radushkevich) and three-parameter (Redlich-Peterson, Toth, Sips, and Khan)

554 isotherm models, with goodness of fit determined using the nonlinear regression. Analysis showed

555 that the Sips model provided the best fit of the experimental data, while the maximum adsorption

556 capacity was $180.4 \mathrm{mg} \mathrm{g}^{-1}$, at $303 \mathrm{~K}$ and adsorption was a favourable process. The kinetics of

557 adsorption of Cd(II) onto SDTMA were analysed using pseudo-first-order, pseudo-second-order,

558 Elovich and Bangham kinetic models, with the data described well by the pseudo second-order model,

559 suggesting overall chemical control of the adsorption process, which may be controlled by a

560 combination of physisorption, ion-exchange and complexation. Consequently, SDTMA has been

561 shown to be an effective adsorbent for the removal of $\mathrm{Cd}(\mathrm{II})$ ions from aqueous solutions, and demonstrates the potential of agricultural wastes in water remediation processes. 
This is a peer-reviewed, accepted author manuscript of the following chapter: Fletcher, A., Hashem, A., Farag, S., Taha, G., Badawy, S., \& Mohamed, L. (Accepted/In press). Non-linear adsorption characteristics of modified pine wood sawdust optimised for adsorption of Cd(II) from aqueous systems. Journal of Environmental Chemical Engineering.

563

564

565

566

567

568

569

570

571

572

573

574

575

576

577

578

579

580

581

582

583

584

585

586

587

588

589

590

591

592

593

594

595

\section{References}

[1] C.B. Godiya, X. Cheng, G. Deng, D. Li, X. Lu

Silk fibroin/polyethylenimine functional hydrogel for metal ion adsorption and upcycling utilization

Journal of Environmental Chemical Engineering, 7(2019) 102806

[2] V.F. Meseguer, J.F. Ortuño, M.I. Aguilar, M.L. Pinzón-Bedoya, M. Lloréns, J. Sáez, A.B. Pérez-Marín Biosorption of cadmium (II) from aqueous solutions by natural and modified non-living leaves of Posidonia oceanica

Environmental Science and Pollution Research, 23 (2016) 24032-24046.

[3] X Xie, H Gao, X Luo, T Su, Y Zhang, Z Qin

Polyethyleneimine modified activated carbon for adsorption of $\mathrm{Cd}(\mathrm{II})$ in aqueous solution Journal of Environmental Chemical Engineering, 7 (2019) 103183

[4] A. Usman, A. Sallam, M. Zhang, M. Vithanage, M. Ahmad, A. Al-Farraj, Y.S. Ok, A. Abduljabbar, M. Al-Wabel

Sorption process of date palm biochar for aqueous Cd (II) removal: Efficiency and mechanisms Water, Air, \& Soil Pollution, 227 (2016) 449.

[5] P.B. Vilela, C.A. Matias, A. Dalalibera, V. A. Becegato, A.T. Paulino

Polyacrylic acid-based and chitosan-based hydrogels for adsorption of cadmium: Equilibrium isotherm, kinetic and thermodynamic studies.

Journal of Environmental Chemical Engineering 7 (2019) 103327

[6] A. Hashem, A. Al-Anwar, N.M. Nagy D.M. Hussein, S. Eisa

Isotherms and kinetic studies on adsorption of $\mathrm{Hg}$ (II) ions onto Ziziphus spina-christi L. from aqueous solutions

Green Processing and Synthesis, 5 (2016) 213-224.

[7] A. Hashem, H.A. Hammad, A. Al-Anwar

Modified Camelorum tree particles as a new adsorbent for adsorption of $\mathrm{Hg}$ (II) from aqueous solutions: kinetics, thermodynamics and non-linear isotherms

Desalination and Water Treatment, 57 (2016) 23827-23843.

[8] J.-S. Kwon, S.-T. Yun, J.-H. Lee, S.-O. Kim, H.Y. Jo

Removal of divalent heavy metals ( $\mathrm{Cd}, \mathrm{Cu}, \mathrm{Pb}$, and $\mathrm{Zn}$ ) and arsenic (III) from aqueous solutions using scoria: kinetics and equilibria of sorption

Journal of Hazardous Materials, 174 (2010) 307-313.

[9] A. Khalil, H. Sokker, A. Al-Anwar, A.A. El-Zaher, A. Hashem 
This is a peer-reviewed, accepted author manuscript of the following chapter: Fletcher, A., Hashem, A., Farag, S., Taha, G., Badawy, S., \& Mohamed, L. (Accepted/In press). Non-linear adsorption characteristics of modified pine wood sawdust optimised for adsorption of Cd(II) from aqueous systems. Journal of Environmental Chemical Engineering.

596

597

598

599

600

601

602

603

604

605

606

607

608

609

610

611

612

613

614

615

616

617

618

619

620

621

622

623

624

625

626

627

Preparation, Characterization and Utilization of Amidoximated Poly (AN/MAA)-grafted Alhagi Residues for the Removal of $\mathrm{Zn}$ (II) Ions from Aqueous Solution

Adsorption Science \& Technology, 27 (2009) 363-382.

[10] X. Chen, R. Xu, Y. Xu, H. Hu, S. Pan, H. Pan

Natural adsorbent based on sawdust for removing impurities in waste lubricants

Journal of hazardous materials, 350 (2018) 38-45.

[11] S. Sirusbakht, L. Vafajoo, S. Soltani, S. Habibi

\section{Sawdust Bio sorption of Chromium (VI) Ions from Aqueous Solutions}

Chemical Engineering Transactions, 70 (2018) 1147-1152.

[12] A. Hashem, A. Azzeer, A. Ayoub

The Removal of $\mathrm{Hg}$ (II) lons from Laboratory Wastewater onto Phosphorylated Haloxylon ammodendron: Kinetic and Equilibrium Studies

Polymer-Plastics Technology and Engineering, 49 (2010) 1463-1472.

[13] T.S. Anirudhan, M.K. Sreedhar

Adsorption thermodynamics of Co(II) on polysulphide treated sawdust

Indian J. Chem. Technol. 5 (1998) 41.

[14] C. Raji, T.S. Anirudhan

Copper-impregnated sawdust carbon for the treatment of as (III) rich water J. Sci. Ind. Res. 57 (1998) 10.

[15] M. Ajmal, R.A. Rao, B.A. Siddiiqui

Studies on removal and recovery of $\mathrm{Cr}(\mathrm{VI})$ from electroplating wastes

Water Res. 30 (1996) 1478.

[16] S.R. Shukla, V.D. Sakhardande

Studies on metal ion removal by dyed cellulosic materials

Appl. Polym. Sci. 44 (1992) 903

[17] R. Suemitsu, M. Osako, N. Tagiri

Use of dye-treated sawdust for removal of heavy metals from wastewater

Sci. Eng. Rev. 27 (1986) 41

[18] K.S. Low, C.K. Lee, S.M. Make

Sorption of copper and lead by citric acid modified wood

Wood Science and Technology 38(2004) 629-640.

[19] M. Marchetti, A. Clement, B. Loubinoux, P. Gerardin 
This is a peer-reviewed, accepted author manuscript of the following chapter: Fletcher, A., Hashem, A., Farag, S., Taha, G., Badawy, S., \& Mohamed, L. (Accepted/In press). Non-linear adsorption characteristics of modified pine wood sawdust optimised for adsorption of Cd(II) from aqueous systems. Journal of Environmental Chemical Engineering.

Decontamination of synthetic solutions containing heavy metals using chemically modified sawdusts bearing polyacrylic acid chains

Journal of Wood Science, 46(200) 331-333.

[20] R. Saliba, H. Gauthier, R. Gauthier

Adsorption of heavy metal ions on virgin and chemically-modified lignocellulosic materials Adsorption Science and Technology 23 (2005) 313-322

[21] M. Gaey, V. Marchetti, A. Clement, B. Loubinoux, P. Gerardin

Decontamination of synthetic solutions containing heavy metals using chemically modified sawdusts bearing polyacrylic acid chains. Journal of Wood Science 46(2000) 331-333.

[22] G. Limousin, J.P. Gaudet, L. Charlet, S. Szenknect, V. Barthes, M. Krimissa

\section{Sorption isotherms: a review on physical bases, modeling and measurement}

Appl. Geochem. 22 (2007) 249-275

[23] S.J. Allen, G. Mckay, J.F. Porter

Adsorption isotherm models for basic dye adsorption by peat in single and binary component systems

J. Colloid Interface Sci. 280 (2004) 322-333

[24] M. Khalil, A. Hashem, A. Hebeish

\section{Carboxymethylation of maize starch}

Starch-Stärke, 42 (1990) 60-63

[25] I. Langmuir

The constitution and fundamental properties of solids and liquids. Part I. Solids Journal of the American chemical society, 38 (1916) 2221-2295.

[26] K.R. Hall, L.C. Eagleton, A. Acrivos, T. Vermeulen

\section{Pore-and solid-diffusion kinetics in fixed-bed adsorption under constant-pattern conditions} Industrial \& Engineering Chemistry Fundamentals, 5 (1966) 212-223.

[27] H. Freundlich

\section{Über die adsorption in lösungen}

Zeitschrift für physikalische Chemie, 57 (1907) 385-470.

[28] M. Temkin

\section{Kinetics of ammonia synthesis on promoted iron catalysts}

Acta physiochim. URSS, 12 (1940) 327-356.

[29] M. Dubinin

The equation of the characteristic curve of activated charcoal 
This is a peer-reviewed, accepted author manuscript of the following chapter: Fletcher, A., Hashem, A., Farag, S., Taha, G., Badawy, S., \& Mohamed, L. (Accepted/In press). Non-linear adsorption characteristics of modified pine wood sawdust optimised for adsorption of Cd(II) from aqueous systems. Journal of Environmental Chemical Engineering.

661

662

663

664

665

666

667

668

669

670

671

672

673

674

675

676

677

678

679

680

681

682

Dokl. Akad. Nauk. SSSR., 1947, pp. 327-329.

[30] O. Redlich, D.L. Peterson

\section{A useful adsorption isotherm}

Journal of Physical Chemistry, 63 (1959) 1024-1024.

[31] J. Toth

State equation of the solid-gas interface layers

Acta chim. hung., 69 (1971) 311-328.

[32] R. Sips

On the structure of a catalyst surface

The Journal of Chemical Physics, 16 (1948) 490-495

[33] A. Khan, R. Ataullah, A. Al-Haddad

Equilibrium adsorption studies of some aromatic pollutants from dilute aqueous solutions on activated carbon at different temperatures

Journal of colloid and interface science, 194 (1997) 154-165.

[34] M. Hossain, H. Ngo, W. Guo

Introductory of Microsoft Excel SOLVER function-spreadsheet method for isotherm and kinetics modelling of metals biosorption in water and wastewater

Journal of Water Sustainability, 3(2013) 223-237

[35] A. Kapoor, R. Yang

Correlation of equilibrium adsorption data of condensible vapours on porous adsorbents Gas Separation \& Purification, 3 (1989) 187-192.

[36] S. Karaca, A. Gürses, M. Ejder, M. Açıkyıldız

Kinetic modeling of liquid-phase adsorption of phosphate on dolomite Journal of Colloid and Interface Science, 277 (2004) 257-263.

[37] J. Ng, W. Cheung, G. McKay

Equilibrium studies of the sorption of $\mathrm{Cu}$ (II) ions onto chitosan

Journal of Colloid and Interface Science, 255 (2002) 64-74

[38] S. Rangabhashiyam, N. Anu, M.G. Nandagopal, N. Selvaraju

Relevance of isotherm models in biosorption of pollutants by agricultural byproducts Journal of Environmental Chemical Engineering, 2 (2014) 398-414.

[39] S.K. Lagergren

About the theory of so-called adsorption of soluble substances

Sven. Vetenskapsakad Handingarl, 24 (1898) 1-39 
This is a peer-reviewed, accepted author manuscript of the following chapter: Fletcher, A., Hashem, A., Farag, S., Taha, G., Badawy, S., \& Mohamed, L. (Accepted/In press). Non-linear adsorption characteristics of modified pine wood sawdust optimised for adsorption of Cd(II) from aqueous systems. Journal of Environmental Chemical Engineering.

694

695

696

697

698

699

700

701

702

703

704

705

706

707

708

709

710

711

712

[40] P. Barkakati, A. Begum, M.L. Das, P.G. Rao

Adsorptive separation of Ginsenoside from aqueous solution by polymeric resins: Equilibrium, kinetic and thermodynamic studies

Chemical Engineering Journal, 161 (2010) 34-45.

[41] C. Aharoni, M. Ungarish

Kinetics of activated chemisorption. Part 1.-The non-elovichian part of the isotherm

Journal of the Chemical Society, Faraday Transactions 1: Physical Chemistry in Condensed Phases, 72 (1976) 400-408.

[42] W. Gan, L. Gao, X. Zhan, J. Li

Preparation of thiol-functionalized magnetic sawdust composites as an adsorbent to remove heavy metal ions

Rsc Advances, 6 (2016) 37600-37609

[43] M.L. Dianu, A. Kriza, N. Stanica, A.M. Musuc

Transition metal M (II) complexes with isonicotinic acid 2-(9-anthrylmethylene)-hydrazide

J. Serb. Chem. Soc, 75 (2010) 1515-1531.

[44] C. Teaca, R. Bodîrlau, I. Spiridon

\begin{abstract}
Maleic anhydride treatment of softwood-effect on wood structure and properties
\end{abstract}
Cellulose Chem. Technol., 48 (2014) 863-868

[45] B. Hermawan, S. Nikmatin, Sudaryanto, H. Alatas, S.G. Sukaryo

Effect of oil palm empty fruit bunches fibers reinforced polymer recycled

Materials Science and Engineering 223 (2017) 012064

[46] B. Hermawan, S. Nikmatin, H. Alatas, Sudaryanto, S.G. Sukaryo

Molecular analysis on the utilization of oil palm empty fruit bunches fiber as reinforcement for acrylonitrile butadiene styrene biocomposites

Earth and Environmental Science 65 (2017) 012028

[47] A. Hashem, A. Abdel-Lateff, S. Farag, D. Hussein

Treatment of alhagi residues with tartaric acid for the removal of $\mathrm{Zn}$ (II) ions from aqueous solution

Adsorption Science \& Technology, 26 (2008) 661-678

[48] O. Hamdaoui

Batch study of liquid-phase adsorption of methylene blue using cedar sawdust and crushed brick Journal of hazardous materials, 135 (2006) 264-273.

[49] W.W. Ngah, L. Teong, R. Toh, M. Hanafiah 
This is a peer-reviewed, accepted author manuscript of the following chapter: Fletcher, A., Hashem, A., Farag, S., Taha, G., Badawy, S., \& Mohamed, L. (Accepted/In press). Non-linear adsorption characteristics of modified pine wood sawdust optimised for adsorption of Cd(II) from aqueous systems. Journal of Environmental Chemical Engineering.

Utilization of chitosan-zeolite composite in the removal of $\mathrm{Cu}$ (II) from aqueous solution: adsorption, desorption and fixed bed column studies

Chemical Engineering Journal, 209 (2012) 46-53.

[50] M. Martín-Lara, F. Hernáinz, M. Calero, G. Blázquez, G. Tenorio

Surface chemistry evaluation of some solid wastes from olive-oil industry used for lead removal from aqueous solutions

Biochemical Engineering Journal, 44 (2009) 151-159

[51] H. Chen, Y. Zhao, A. Wang

Removal of $\mathrm{Cu}$ (II) from aqueous solution by adsorption onto acid-activated palygorskite Journal of Hazardous Materials, 149 (2007) 346-354

[52] A. Hashem, H.A. Hussein, M.A. Sanousy, E. Adam, E.E. Saad

Monomethylolated thiourea-sawdust as a new adsorbent for removal of $\mathrm{Hg}$ (II) from contaminated water: equilibrium kinetic and thermodynamic studies

Polymer-Plastics Technology and Engineering, 50 (2011) 1220-1230

[53] S. Abdel-Aal, Y. Gad, A. Dessouki

\section{The use of wood pulp and radiation-modified starch in wastewater treatment} Journal of applied polymer science, 99 (2006) 2460-2469

[54] S. Andini, R. Cioffi, F. Montagnaro, F. Pisciotta, L. Santoro

Simultaneous adsorption of chlorophenol and heavy metal ions on organophilic bentonite Applied clay science, 31 (2006) 126-133.

[55] N. Azouaou, Z. Sadaoui, A. Djaafri, H. Mokaddem

Adsorption of cadmium from aqueous solution onto untreated coffee grounds: Equilibrium, kinetics and thermodynamics

Journal of hazardous materials, 184 (2010) 126-134

[56] N. Balkaya, H. Cesur

\section{Adsorption of cadmium from aqueous solution by phosphogypsum}

Chemical engineering journal, 140 (2008) 247-254.

[57] M.S. Berber-Mendoza, R. Leyva-Ramos, P. Alonso-Davila, J. Mendoza-Barron, P.E. Diaz-Flores

Effect of $\mathrm{pH}$ and temperature on the ion-exchange isotherm of $\mathrm{Cd}$ (II) and $\mathrm{Pb}$ (II) on clinoptilolite Journal of Chemical Technology \& Biotechnology: International Research in Process, Environmental \& Clean Technology, 81 (2006) 966-973

[58] A. Borzou, M. Kalbasi, M. Hoodaji, M. Abdouss, A. Mohammadi 
This is a peer-reviewed, accepted author manuscript of the following chapter: Fletcher, A., Hashem, A., Farag, S., Taha, G., Badawy, S., \& Mohamed, L. (Accepted/In press). Non-linear adsorption characteristics of modified pine wood sawdust optimised for adsorption of Cd(II) from aqueous systems. Journal of Environmental Chemical Engineering. fiber

[59] M. Geay, V. Marchetti, A. Clément, B. Loubinoux, P. Gérardin

Decontamination of synthetic solutions containing heavy metals using chemically modified sawdusts bearing polyacrylic acid chains Journal of Wood Science, 46 (2000) 331-333.

[60] R. Say, A. Denizli, M.Y. Arıca

Biosorption of cadmium (II), lead (II) and copper (II) with the filamentous fungus Phanerochaete chrysosporium

Bioresource Technology, 76 (2001) 67-70.

[61] S.M. Dal Bosco, R.S. Jimenez, W.A. Carvalho

Removal of toxic metals from wastewater by Brazilian natural scolecite Journal of Colloid and Interface Science, 281 (2005) 424-431. 